Classificação de aplicações estáveis através do uso de grafos

\author{
Markus Diego Sampaio da Silva Dias
}


Data de Depósito:

Assinatura:

\title{
Classificação de aplicações estáveis através do uso de grafos
}

\author{
Markus Diego Sampaio da Silva Dias
}

Orientador: Prof. Dr. Marcelo José Saia

Dissertação apresentada ao Instituto de Ciências Matemáticas e de Computação - ICMC-USP, como parte dos requisitos para obtenção do título de Mestre em Ciências - Matemática . VERSÃO REVISADA

USP - São Carlos

Maio de 2012 
Ficha catalográfica elaborada pela Biblioteca Prof. Achille Bassi e Seção Técnica de Informática, ICMC/USP, com os dados fornecidos pelo(a) autor(a)

Dias, Markus Diego Sampaio da Silva
Classificaço de aplicaçóes através do uso de
grafos / Markus Diego Sampaio da Silva Dias;
orientador Marcelo José Saia. -- São Carlos, 2012.
64 p.
Dissertação (Mestrado - Programa de Pós-Graduação en
Matemática)-- Instituto de Ciências Matemáticas e
de Computação, Universidade de São Paulo, 2012.
1. Grafos. 2. Aplicações Estáveis. I. Saia,
Marcelo José, orient. II. Título.


"Que os vossos esforços

desafiem as impossibilidades, lembrai-vos de que as grandes coisas do homem foram conquistadas do que parecia impossivel." Charles Chaplin 


\section{Agradecimentos}

Neste momento completo mais uma etapa da minha vida, mais uma etapa desta caminhada que não começou há dois anos atrás com o início do mestrado, ou há seis anos atrás quando comecei a cursar matemática. E certamente não participei dessa caminhada sozinho. Em vários momentos houveram mãos para me empurrar para frente quando eu estava parando, para me levantar quando eu estava caindo, houveram ouvidos para escutar minhas palavras quando estava me perdendo e bocas para me aconselhar no melhor caminho. Pessoas caminharam comigo ao meu lado, nos momentos bons e nos momentos ruins, algumas que traçaram outro caminho a partir de certo ponto e outras que estão me esperando um pouco mais à frente. Mas todas elas tiveram a sua importância e é a elas que eu agradeço essa dissertação, pois em cada letra deste trabalho existe um pouco de cada uma delas.

Agradeço aos meus pais que estão comigo desde que nasci, por me criarem, pela educação. À minha mãe Jacqueline Sampaio, pelo amor incondicional e independente do que eu faça. Ao meu pai Marco Cesar, por sempre lutar pela minha formação e pela figura de homem. Eles são as peças vitais por eu estar aqui hoje e dedico a eles mais que a ninguém.

Ao meu irmão Gabriel Sampaio pela companhia, pelas horas jogando videogame e assistindo Naruto, pelas frases engraçadas e por todas as brigas que dão mais emoção à nossa vida.

Às minhas madrinhas, tias, tios, primos, avôs, avós e a todo o resto de minha família. Aos que estão aqui e a aqueles que já se foram. Por todos os momentos em família, pelos meus cuidados, pelas risadas, abraços e carinho. 
Ao meu orientador Marcelo José Saia, por todas as horas de estudo, pelo aprendizado durante esses dois anos de mestrado, pela amizade e principalmente pela paciência que teve comigo.

À minha orientadora de iniciação científica Maria Aparecida Ruas, pelos anos de estudo durante a graduação, por todos os conselhos que me deu durante aqueles anos em vários dos meus momentos de dúvida sobre o que fazer. Pela força, pela grande companheira e mãezona que foi durante minha graduação.

À Cíntia Rejane Consonni, pelos momentos que passamos juntos, por me apoiar, estar ao meu lado, me acalmar quando eu estive nervoso ou desesperado, ser meu ponto de segurança, pela paciência com a minha pessoa, pela companheira, amiga e namorada que ela é. Obrigado por ter entrado junto comigo na minha caminhada e também por todos os momentos da caminhada que ainda estão por vir. Agradeço também a todos da sua família por me tratarem tão bem.

Agradeço a todos aos meus amigos da sala de mestrado. Em especial Henrique Costa pelo grande amigo que foi durante esses seis anos, Camila Mariana Ruiz que foi como uma irmã para mim durante todos esses anos e Júlia Borges pela grande amizade e por cuidar de mim. Ao Rodolfo Collegari, Jackson Itikawa e Luan Ferreira pelos seis anos de convivência aqui na USP. Pelos que entraram mais tarde já no mestrado e se tornaram grandes amigos: Rodrigo Lopes, Steve Vicentin, Leandro Antunes, Dione Andrade e Jaqueline Ferreira. E a todos os outros que mesmo sem tanta convivência me ajudaram muito: Eber Vizarreta, Renan Gutierrez, César Augusto, Jorge Huarcaya, José Alvites, Pavel Jesus.

Aos meus amigos durante esses anos de ICMC: Fernando Trevisani, Carlos Celestino, Noemi Rocha, Felipe Louza, Matheus Menes, Edgard Lourenço, João Neto, João Paulo Poli, Guto Fioruci, Juliana Dionisio, Juliana Theodoro, Gabriel Ponce, Camilo Campana, Matheus Bortolan, Alex Rezende, Thaís Dalbelo, todos outros companheiros da minha sala de graduação, a turma do vôlei, a turma do futebol e todos os outros que eu possa ter esquecido de mencionar. Obrigado pelos momentos durante a faculdade.

Aos meus amigos de Franca: Hugo Iounchan pela amizade de 12 anos, Israel Bittencourt, Deivid Migueleti, Suellen Migueleti, Lucas Chaves que são amigos meus até hoje apesar da distância e à todos os outros que estudei no Objetivo, em especial Rafael Gus- 
tavo e Tauana Takatu, amigos do CCAA e todos por onde eu estudei. E aos meus amigos de quando morava em Cristais Paulista pela infância feliz que tive.

Aos meus cães Katucha, Kiara, Thunder e Nell por todos os momentos de diversão por mais de uma década, que muitas vezes me escutaram sentados juntos ao meu lado e que depois de tanto tempo se tornaram da família.

Agradeço também a todos os outros professores e funcionários do ICMC por tornarem a minha jornada por aqui possível e pelo trabalho dedicado.

Agradeço à Coordenação de Aperfeiçoamento de Pessoal de Nível Superior (CAPES) pelos dois primeiros meses de bolsa de Mestrado e ao Conselho Nacional de Desenvolvimento Científico e Tecnológico (CNPQ) pelos demais meses de suporte financeiro.

Eu só tenho a dizer a todos vocês muito obrigado e desculpe aqueles que eu possa ter esquecido de mencionar aqui. E junto com vocês vou continuar caminhando nessa nova etapa que será o doutorado, lembrando sempre que não é porque as coisas acontecem de uma forma diferente da que esperamos que elas serão ruins. Você apenas tomou um caminho diferente, mas o que estará lá na frente poderá ser muito melhor e se conseguido com esforço e dedicação será muito mais gratificante. Por isso nunca desistam e eu espero estar aqui para ajudar e retribuir a todos com o máximo que eu puder. 


\section{Resumo}

Neste projeto inicia-se o estudo de classificação de aplicações estáveis. Para isto usamos grafos que irão corresponder ao conjunto singular destas aplicações. Em um primeiro momento estudamos o caso de aplicações estáveis de superfícies no plano e depois estudamos aplicações estáveis de 3 -variedades em $\mathbb{R}^{3}$.

Palavras-chave: Aplicações estáveis e grafos. 


\section{Abstract}

In this project we began the study of classification of stable maps. For this we use graphs that correspond to the singular set of these applications. At first we study the case of stable maps of surfaces in the plane and then we study stable maps of a 3-manifold in $\mathbb{R}^{3}$.

Key words: Stables maps and graphs. 


\section{Sumário}

Introdução

1 Preliminares 5

1.1 Aplicações estáveis . . . . . . . . . . . . . . . . . 5 5

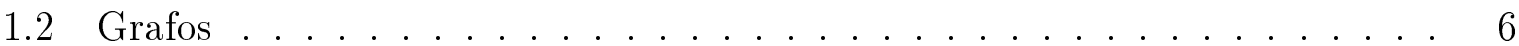

1.3 Homologia . . . . . . . . . . . . . . . . . . . 9

1.3.1 Sequências Exatas . . . . . . . . . . . . . 12

1.4 Poliedros . . . . . . . . . . . . . . . . . . . . . . 14

1.5 Homologia Simplicial . . . . . . . . . . . . . . . . 18

1.5.1 Exemplos de Homologia Simplicial . . . . . . . . . . . . . . 21

1.6 Característica de Euler, Número de Betti e Genus . . . . . . . . . . . . . 24

2 Grafos associados a coleções de curvas fechadas em superfícies $\quad 31$

2.1 Aplicações estáveis de superfícies no plano . . . . . . . . . . . . . 31

2.2 Construção do grafo pesado . . . . . . . . . . . . . . . . . . 33

3 Grafos de aplicações estáveis de uma superfície no plano 39

4 Grafos associados à superfícies em uma 3-variedade $\quad 41$

4.1 Aplicações estáveis de 3 -variedades em $\mathbb{R}^{3} \ldots \ldots$. . . . . . . . . . 41

4.23 -variedades e grafos . . . . . . . . . . . . . . . . . . 42

5 Grafos de aplicações estáveis de 3-variedades em $\mathbb{R}^{3} \quad 51$

5.1 Transições de Codimensão $1 \ldots \ldots$. . . . . . . . . . . . . . 54 
5.2 Cirurgias de Aplicações Estáveis . . . . . . . . . . . . . . . . 58

6 Considerações finais 


\section{Introdução}

Este trabalho insere-se na linha de pesquisa de Invariantes topológicos de aplicações estáveis: Consiste no estudo de invariantes que permitem a classificação global de aplicações estáveis entre variedades. Um dos principais objetos de estudo destes invariantes consiste nos grafos associados, que foi inicialmente desenvolvido por Hacon, Mendes e Romero Fuster para o caso orientável, com extensão ao caso não orientável.

Inicialmente, a título de ilustração, estudamos o caso de aplicações estáveis de superfícies no plano e depois, como principal objetivo estudamos aplicações estáveis de 3-variedades em $\mathbb{R}^{3}$.

Para isto usamos grafos que correspondem ao conjunto singular destas aplicações, que são estudados na seção 1.2. Intuitivamente um grafo é um conjunto finito de pontos no espaço, chamados de vértices do grafo, e alguns pares de vértices são ligados por arcos, chamados de arestas do grafo. Definimos um grafo abstrato orientado e como realizar um grafo em $\mathbb{R}^{n}$. A realização de um grafo abstrato orientado, chamado de grafo orientado, é apenas a realização do grafo abstrato correspondente ordenando cada aresta do grafo de maneira óbvia. Ainda na seção 1.2 vemos as definições de grafo conexo, loops e o conceito de árvore que nada mais é que um grafo sem loops. Definimos um grafo bipartido e vemos um importante resultado que nos diz que um grafo é bipartido se e somente se todo loop tem um número par de arestas.

Para o estudo do caso de aplicações de 3 -variedades em $\mathbb{R}^{3}$ iniciamos na seção 1.3 o estudo sobre grupos de homologia. Estudamos sequências exatas, suas propriedades e definimos a sequência de Mayer-Vietoris. A seguir estudamos poliedros na seção 1.4., que são espaços subjacentes em $\mathbb{R}^{n}$ a algum complexo simplicial. Com estes conceitos 
chegamos à teoria de homologia simplicial na seção 1.5 e vemos exemplos como a homologia de dimensão zero, a homologia do cone e a de uma esfera $S^{n}$ que são usadas para descrever casos mais complexos.

Na seção 1.6 apresentamos conceitos que são usados também na classificação das aplicações estáveis, tais como Característica de Euler, Número de Betti e Genus. Estabelecemos uma conexão entre a Característica de Euler de um poliedro e os grupos de homologia desse poliedro. Devemos ressaltar que é possível definirmos a característica de Euler sem mencionar grupos de homologia, mas o único modo de falar sobre invariância topológica é usando a teoria de homologia. Essa conexão é feita usando os números de Betti.

No capítulo 2 estudamos a realização de um par superfície e família de curvas em um grafo pesado. No caso de aplicações estáveis de uma superfície no plano o conjunto singular dessa aplicação $f$ consiste de uma quantidade finita de curvas fechadas mergulhadas disjuntas de $M$. O conjunto discriminante consiste de um número finito de curvas planas imersas com cúspides, intersecções transversais e auto-intersecções (disjuntas do conjunto de cúspides).

O conjunto singular $\sum f$ é um invariante isotópico de aplicações estáveis. Portanto o número de componentes conexas de $\sum f$, bem como o tipo topológico de seu complemento em M também são invariantes isotópicos. Daí a ideia de termos um grafo pesado onde toda essa informação é guardada. A partir do grafo o par $M, \sum f$ pode ser reconstruído (a menos de equivalência). E então no capítulos 3 estudamos os grafos no caso em que as famílias de curvas são os conjuntos singulares destas aplicações.

No capítulo 4 é feito um trabalho semelhante ao do capítulo 2. Contudo é realizado o grafo pesado de uma 3-variedade com superfícies disjuntas mergulhadas, pois o conjunto singular $\sum f$ de uma aplicação estável $f$ consiste de superfícies disjuntas mergulhadas. Cada superfícies consiste de pontos de dobra juntos com curvas de pontos de (i.e. pontos cuja a imagem é um ponto de cúspide do conjunto discriminante $f\left(\sum f\right)$ ), onde podem existir pontos de rabo de andorinha isolados. Além disso vemos alguns resultados que permitem a classificação e realização das 3-variedades com superfícies mergulhadas em grafos como o resultado a seguir:

Qualquer grafo pesado pode ser visto como o grafo de alguma coleção de superfícies fechadas mergulhadas em uma 3-variedade. 
Agora, dada uma aplicação estável $f: M \rightarrow \mathbb{R}^{3}$, vamos considerar o conjunto singular de $f$ como a coleção de superfícies para construirmos o grafo. O grafo correspondente é definido como o grafo de $f$.

Não é difícil ver que, como no caso de aplicações estáveis de superfícies orientáveis fechadas no planos, se uma 3-variedade $M$ é orientável, então o grafo de qualquer aplicação estável de $M$ em $\mathbb{R}^{3}$ precisa ser bipartido, pois cada componente do conjunto singular separa (globalmente) $M$ em regiões diferentes, uma em que preserva a orientação e outra em que reverte. Deste modo aparecem várias questões que podem ser feitas:

- Qualquer grafo pode ser representado por uma aplicação estável de uma 3-variedade fechada em $\mathbb{R}^{3}$ ?

- Qualquer coleção de superfícies fechadas disjuntas mergulhadas em uma 3-variedade fechada $M$ pode ser o conjunto singular de uma aplicação estável de $M$ em $\mathbb{R}^{3}$ ?

- Quais são todos os possíveis grafos para aplicações estáveis de uma dada 3-variedade fechada $M$ em $\mathbb{R}^{3}$ ?

- Para um dado grafo $\mathcal{G}$, como construir diferentes $\mathcal{A}$ - classes de aplicações estáveis em $M$ cujo grafo seja $\mathcal{G}$ ?

Este estudo é feito no capítulo 5 usando resultados como o teorema de Eliashberg e conceitos como superfície de Heegaard. Além disso estudamos transições de codimensão 1 e cirurgias vendo como elas afetam o grafo resultante de cada aplicação. 


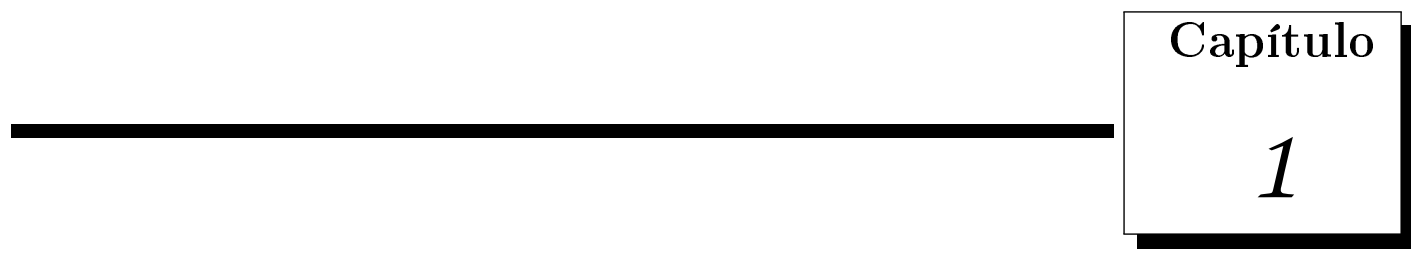

\section{Preliminares}

\subsection{Aplicações estáveis}

Para as definições a seguir consideremos $M$ e $N$ como duas superfícies orientáveis compactas com fronteira vazia de dimensões $m$ e $n$ respectivamente. Seja $C^{\infty}(M, N)$ o conjunto de todas as aplicações de classe $C^{\infty}$ com domínio em $M$ e contradomínio em $N$.

Definição 1.1.1. Duas aplicações suaves $f$ e g pertencentes à $C^{\infty}(M, N)$ são equivalentes $(f \sim g)$ se existem difeomorfismos $l: M \rightarrow M$ e $k: N \rightarrow N$ tais que $k \circ f=l \circ g$.

Definição 1.1.2. A topologia $C^{\infty}$ de Whitney em $C^{\infty}(M, N)$ é definida da seguinte forma: Seja $\epsilon>0$, então uma vizinnhança fundamental de $f \in C^{\infty}(M, N)$ é o conjunto

$$
\left\{g \in C^{\infty}(M, N): \sum_{|\alpha|=1}^{\infty}\left|\frac{\partial^{|\alpha|} f}{\partial x^{\alpha}}-\frac{\partial^{|\alpha|} g}{\partial x^{\alpha}}\right|<\epsilon\right\}
$$

onde $\alpha$ percorre todas as $m$-uplas de números naturais $\alpha=\left(\alpha_{1}, \ldots, \alpha_{m}\right)$ e tal que $|\alpha|=$ $\alpha_{1}+\ldots+\alpha_{m}$. Além disso,

$$
\frac{\partial^{|\alpha|} f}{\partial x^{\alpha}}=\frac{\partial^{|\alpha|} f}{\partial x_{\alpha_{1}} \ldots \partial x_{\alpha_{m}}} .
$$

Definição 1.1.3. Uma aplicação suave $f$ é estável se todas as aplicações suficientemente próximas à $f$ (no sentido da topologia $C^{\infty}$ de Whitney) são equivalentes à $f$. 
Definição 1.1.4. Um ponto singular (ou uma singularidade) de uma aplicação $f: M \rightarrow$ $N$ é um ponto $x \in N$ em que o germe é singular (O germe é chamado singular quando não é uma imersão e nem uma submersão).

Definição 1.1.5. O conjunto singular $\sum f$ de uma aplicação $f: M \rightarrow N$ é o conjunto de todos os pontos singulares de $f$.

Definição 1.1.6. Seja $\sum f$ o conjunto singular de $f$. Chamamos a imagem deste conjunto pela função $f$ de conjunto discriminante de $f$.

\subsection{Grafos}

Intuitivamente um grafo é um conjunto finito de pontos no espaço, chamados de vértices do grafo, e alguns pares de vértices são ligados por arcos, chamados de arestas do grafo. Dois arcos se encontram apenas em um vértice, nenhuma aresta liga um vértice a si mesmo e dois vértices nunca são conectados por mais de uma aresta. A posição dos vértices e o comprimento das arestas não são importantes; o que nos importa é o número de vértices e os pares de vértices que são ligados por uma aresta. Assim temos a seguinte definição:

Definição 1.2.1. Um grafo abstrato é um par $(V, E)$ em que $V$ é um conjunto finito e $E$ é um conjunto de pares não ordenados de elementos distintos de V. Então um elemento de E é da forma $\{v, w\}$ em que ve w pertencem a $V$ e $v \neq w$. Os elementos de $v$ são chamados de vértices e o elemento $\{v, w\}$ de E é chamado de aresta que conecta $v$ e $w$.

Exemplo: Seja $V=\{u, v, w\}$ e $E=\{\{u, v\},\{u, w\}\}$. Este grafo abstrato pode ser desenhado, ou "realizado" como na figura 1.

Definição 1.2.2. Um grafo abstrato orientado é um par $(V, E)$ em que $V$ é um conjunto finito e E é um conjunto de pares ordenados de elementos distintos de $V$ com a propriedade de que se $(v, w) \in E$ então $(w, v) \notin E$. Os elementos de $v$ são chamados de vértices e o elemento $\{v, w\}$ de $E$ é chamado de aresta que liga $v \grave{a} w$. 


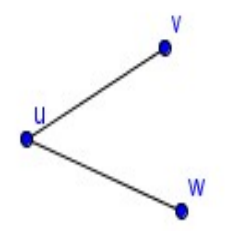

\section{Figura 1: Exemplo de grafo.}

Definição 1.2.3. Seja (V,E) um grafo abstrato. Uma realização de $(V, E)$ é um conjunto de pontos em um espaço vetorial real $\mathbb{R}^{n}$, um ponto para cada vértice, ligados por segmentos unindo precisamente aqueles pares de pontos que correspondem às arestas. Os pontos são chamados de vértices e os segmentos de arestas; a realização é chamada de grafo. Exigimos as seguintes condições:

(i) duas arestas se encontram, no máximo, em um ponto final, e

(ii) nenhum vértice pertence à uma aresta exceto aqueles que são pontos finais.

$A$ aresta ligando $v$ e w é denotada como (vw) ou (wv).

A realização de um grafo abstrato orientado, chamado de grafo orientado, é apenas a realização do grafo abstrato correspondente ordenando cada aresta do grafo de maneira óbvia.

Teorema 1.2.1. [2] Todo grafo abstrato pode ser realizado em $\mathbb{R}^{3}$.

Definição 1.2.4. Dois grafos abstratos $(V, E)$ e ( $\left.V^{\prime}, E^{\prime}\right)$ são dito isomorfos se existe uma aplicação bijetora $f: V \rightarrow V^{\prime}$ tal que

$$
\{v, w\} \in E \Leftrightarrow\{f(v), f(w)\} \in E^{\prime} .
$$

Dois grafos são ditos isormorfos se são realizações de grafos abstratos isomofos.

Definição 1.2.5. Um caminho em um grafo $\mathcal{G}$ de $v^{1}$ até $v^{n}$ é uma sequência de vértices e arestas $v^{1} e^{1} v^{2} e^{2} \ldots v^{n} e^{n} v^{n+1}$ em que $e^{r}=\left(v^{r}, v^{r+1}\right)$. O caminho é chamado simples se as arestas são todas distintas e os vértices são todos distintos exceto possivelmente o vértice inicial e final do caminho. Se isto acontece ele é chamado um loop. 
Definição 1.2.6. Um grafo $\mathcal{G}$ é conexo se, dados quaisquer dois vértices v e w de $\mathcal{G}$ existe um caminho de $v$ até $w$.

Definição 1.2.7. Um grafo conexo que não possui loops é chamado de árvore.

Exemplo: Na figura 2 o grafo da esquerda é uma árvore, mas grafo o da direita não é uma árvore.
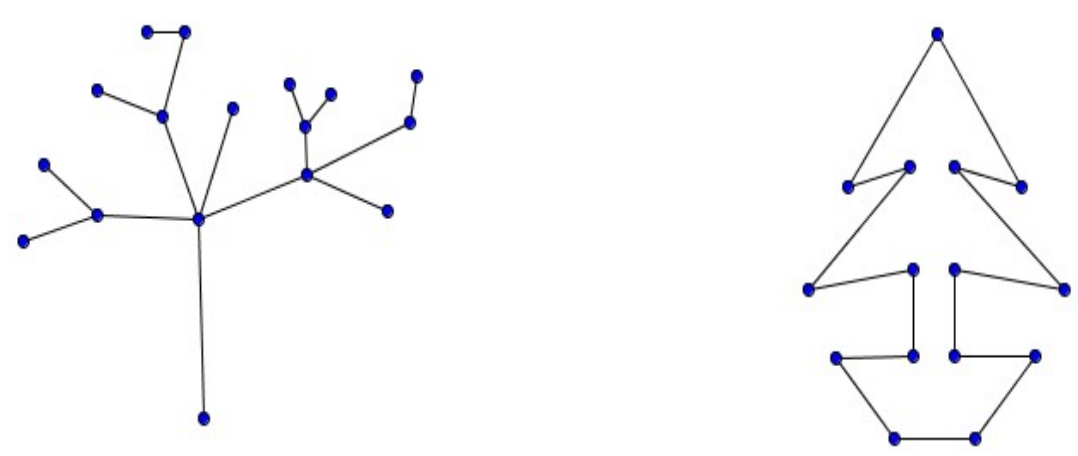

Figura 2

Definição 1.2.8. Dado um grafo $\mathcal{G}$, um grafo $\mathcal{H}$ é chamado um subgrafo de $\mathcal{G}$ se os vértices de $\mathcal{H}$ são vértices de $\mathcal{G}$ e as arestas de $\mathcal{H}$ são arestas de $\mathcal{G}$. $\mathcal{H}$ é um subgrafo próprio de $\mathcal{G}$ se $\mathcal{H} \neq \mathcal{G}$.

Todo grafo $\mathcal{G}$ terá um subgrafo que é uma árvore. Então o conjunto $\Im$ dos subgrafos de $\mathcal{G}$ que são árvores terá elementos maximais. Isto é, existirá pelo menos uma árvore $\mathcal{T} \in \Im$ tal que $\mathcal{T}$ não é um subgrafo próprio de nenhum $\mathcal{T}^{\prime} \in \Im$.

Definição 1.2.9. Uma árvore definida como acima é chamada de árvore maximal.

Proposição 1.2.2. Seja $\mathcal{G}$ um grafo conexo. Um subgrafo $\mathcal{T}$ de $\mathcal{G}$ é uma árvore maximal de $\mathcal{G}$ se e somente se $\mathcal{T}$ é uma árvore e contêm todos os vértices de $\mathcal{G}$.

Definição 1.2.10. Seja $\mathcal{G}$ um grafo conexo com $\alpha_{0}$ vértices e $\alpha_{1}$ arestas. O número ciclomático de $\mathcal{G}$ é o inteiro

$$
\mu=\alpha_{1}-\alpha_{0}+1
$$


Teorema 1.2.3. Seja $\mathcal{G}$ um grafo com número ciclomático $\mu$. Então:

(1) $\mu \geq 0$;

(2) $\mu=0$ se e somente se $\mathcal{G}$ é uma árvore;

(3) Toda árvore maximal de $\mathcal{G}$ tem $\alpha_{1}-\mu$ arestas. Isto é, toda árvore maximal pode ser obtida a partir de $\mathcal{G}$ removendo $\mu$ arestas convenientes (e nenhum vértice).

Observação 1. Seja $\mathcal{G}$ um grafo com $\mu(\mathcal{G})=1$. Então $\mathcal{G}$ tem exatamente 1 loop.

Demonstração: Pelo teorema acima $\mathcal{G}$ tem pelo menos um loop já que $\mu(\mathcal{G})>0$. Se $\mathcal{G}$ tem pelo menos dois loops, seja $e$ uma aresta de um loop que não passa pelo outro loop. Retirando $e$ de $\mathcal{G}$ deixa $\mathcal{G}$ conexo, e ainda contendo um loop, mas isto diminui $\mu$ em um, tornando ele zero. O que é uma contradição ao teorema.

Observação 2. Loops Básicos: Sejam $\mathcal{G}$ um grafo conexo com número ciclomático $\mu$ e $e^{1}, \ldots, e^{\mu}$ arestas que quando removidas de $\mathcal{G}$ ele se torna uma árvore maximal $\mathcal{T}$ (teorema anterior). Seja $\mathcal{T}+e^{i}$ o grafo obtido adicionando a aresta $e^{i} \grave{a} \mathcal{T}$. Então $\mu\left(\mathcal{T}+e^{i}\right)=1$ e pela observação acima existe um único loop $l^{i}$ em $\mathcal{T}+e^{i}$. Então o número ciclomático determina o número de loops de um grafo conexo.

Definição 1.2.11. Um grafo $\mathcal{G}$ é chamado bipartido se o seu conjunto de vértices pode ser particionado em dois subconjuntos distintos $V_{1}, V_{2}$ de maneira que toda aresta de $\mathcal{G}$ liga um vértice de $V_{1}$ a um vértice de $V_{2}$.

Teorema 1.2.4. Um grafo é bipartido se e somente se todo loop tem um número par de arestas.

\subsection{Homologia}

Seja A um anel comutativo com unidade.

Definição 1.3.1. Um complexo de cadeias com coeficientes em $A$ é uma sequência $\mathcal{C}=$ $\left(C_{p}, \partial_{p}\right)$ de A-módulos $C_{p}, p \geq 0$, inteiro, e homomorfismos $\partial_{p}: C_{p} \rightarrow C_{p-1}$ tais que $\partial_{p} \circ \partial_{p-1}=0$. 
Para representar este complexo de cadeias usamos a seguinte notação

$$
\mathcal{C}: \cdots \rightarrow C_{p+1} \stackrel{\partial_{p+1}}{\longrightarrow} C_{p} \stackrel{\partial_{p}}{\longrightarrow} C_{p-1} \rightarrow \cdots \rightarrow C_{1} \stackrel{\partial_{1}}{\longrightarrow} C_{0} \stackrel{\partial_{0}}{\longrightarrow} 0
$$

Definição 1.3.2. Cada elemento $x \in C_{p}$ é chamado uma $p$-cadeia ou uma cadeia de dimensão p. Se $\partial_{p} x=0$, diz-se que $x$ é um p-ciclo ou simplesmente um ciclo.

O conjunto $Z_{p}$ dos p-ciclos é um submódulo de $C_{p}$. De fato, $Z_{p}$ é o núcleo do homomorfismo $\partial_{p}: C_{p} \rightarrow C_{p-1}$.

Definição 1.3.3. Se $y=\partial_{p+1} x$, diz-se que a p-cadeia y é o bordo da $(p+1)$-cadeia $x$.

O conjunto $B_{p}$ das p-cadeias que são bordos de $(\mathrm{p}+1)$-cadeias é um submódulo de $C_{p}$; $B_{p}$ é a imagem do homomorfismo $\partial_{p+1}: C_{p+1} \rightarrow C_{p}$.

Cada homomorfismo $\partial_{p}: C_{p} \rightarrow C_{p-1}$ é chamado de operador-bordo. A menos que seja necessário ser mais explícito, escreve-se $\partial$ em vez de $\partial_{p}$, de modo que $\partial \partial x=0$ para toda cadeia $x \in C_{p}$. Desta relação vemos que $B_{p} \subset Z_{p}$.

Definição 1.3.4. O A-módulo quociente $H_{p}=H_{p}(\mathcal{C})=Z_{p} / B_{p}$ chama-se o grupo de homologia p-dimensional do complexo $\mathcal{C}$ com coeficientes em $A$.

Seus elementos são as classes de homologia

$$
[z]=z+B_{p}=\left\{z+\partial x ; x \in C_{p+1}\right\}
$$

dos ciclos $z \in Z_{p}$.

Se $z$ e $z^{\prime}$ são ciclos p-dimensionais com $[z]=\left[z^{\prime}\right]$, então dizemos que $z$ e $z^{\prime}$ são ciclos homólogos.

Se para cada $p \geq 0$, tivermos um submódulo $C_{p}^{\prime} \subset C_{p}$ tal que $\partial C_{p+1}^{\prime} \subset C_{p}^{\prime}$ então, pondo $\partial_{p}^{\prime}=\partial_{p} \mid C_{p}^{\prime}$, a sequência $\mathcal{C}^{\prime}=\left(C_{p}^{\prime}, \partial_{p}^{\prime}\right)$ é um complexo de cadeias, chamado um subcomplexo de $\mathcal{C}$.

Considerando, para cada $p \geq 0$, o A-módulo quociente $\bar{C}_{p}=C_{p} / C_{p}^{\prime}$, existe um único homomorfismo $\bar{\partial}_{p}: \bar{C}_{p} \rightarrow \bar{C}_{p-1}$ que torna comutativo o diagrama abaixo 


$$
\begin{gathered}
C_{p} \stackrel{\partial_{p}}{\longrightarrow} C_{p-1} \\
\downarrow j \quad j \downarrow \\
\bar{C}_{p} \stackrel{\bar{\partial}_{p}}{\longrightarrow} \bar{C}_{p-1}
\end{gathered}
$$

onde j é a aplicação quociente. Por definição $\bar{\partial}(j x)=j(\partial x)$. Logo, a sequência $\overline{\mathcal{C}}$ é um complexo de cadeias, chamado o quociente de $\mathcal{C}$ por $\mathcal{C}^{\prime}$.

Definição 1.3.5. Sejam $\mathcal{X}=\left(X_{p}, \partial_{p}\right)$ e $\mathcal{N}=\left(Y_{p}, \partial_{p}\right)$ complexos de cadeias, cujos operadores-bordo indicamos com o mesmo símbolo $\partial_{p}=\partial$. Um morfismo $f: \mathcal{X} \rightarrow \mathcal{N}$ é uma sequência de homomorfismos $f_{p}: X_{p} \rightarrow Y_{p}$ tais que $f_{p}(\partial x)=\partial f_{p+1}(x)$ para todo $x \in X_{p}$.

Isto significa que, no diagrama abaixo, todos os retângulos são comutativos

$$
\begin{aligned}
\cdots \rightarrow & X_{p+1} \stackrel{\partial}{\longrightarrow} X_{p} \stackrel{\partial}{\longrightarrow} X_{p-1} \rightarrow \cdots \rightarrow X_{0} \\
& \downarrow f_{p+1} \quad \downarrow f_{p} \quad \downarrow f_{p-1} \quad \downarrow f_{0} \\
& \\
& \rightarrow X_{p+1} \stackrel{\partial}{\longrightarrow} X_{p} \stackrel{\partial}{\longrightarrow} X_{p-1} \rightarrow \cdots \rightarrow X_{0}
\end{aligned}
$$

Segue-se então que $f_{p}$ induz, por passagem ao quociente, um homomorfismo $\left(f_{p}\right)_{*}$ : $H_{p}(\mathcal{X}) \rightarrow H_{p}(\mathcal{N})$, definido por $\left(f_{p}\right)_{*}[z]=\left[f_{p}(z)\right]$ para toda classe $[z] \in H_{p}(\mathcal{X})$ de um ciclo $z \in Z_{p}(\mathcal{X})$.

O homomorfismo induzido $f_{*}: H_{p}(\mathcal{X}) \rightarrow H_{p}(\mathcal{N})$ é natural no seguinte sentido: se $g: \mathcal{N} \rightarrow \mathcal{M}$ é outro morfismo entre complexos de cadeias, induzindo, para cada $p \geq 0$ o homomorfismo $g_{*}: H_{p}(\mathcal{N}) \rightarrow H_{p}(\mathcal{M})$ então o morfismo composto $g \circ f: \mathcal{X} \rightarrow \mathcal{M}$ e tem-se $(g \circ f)_{*}=g_{*} \circ f_{*}$. Evidentemente se $i d: \mathcal{X} \rightarrow \mathcal{X}$ é o morfismo identidade, então $i d_{*}: H_{p}(\mathcal{X}) \rightarrow H_{p}(\mathcal{X})$ é a aplicação identidade.

Segue-se então que o morfismo $f: \mathcal{X} \rightarrow \mathcal{N}$ admite o morfismo inverso $g: \mathcal{N} \rightarrow \mathcal{X}$ e então $f_{*}: H_{p}(\mathcal{X}) \rightarrow H_{p}(\mathcal{N})$ é invertível para todo $p \geq 0$ sendo $\left(f_{*}\right)^{-1}=g_{*}$. 


\subsubsection{Sequências Exatas}

Iniciamos esta seção com a definição de sequência exata que será importante para o nosso estudo.

Definição 1.3.6. Uma sequência de homomorfismos de A-módulos

$$
\longrightarrow M_{p+1} \stackrel{f_{p+1}}{\longrightarrow} M_{p} \stackrel{f_{p}}{\longrightarrow} M_{p-1} \longrightarrow \cdots
$$

chama-se exata quando o núcleo de cada homomorfismo $f_{p}$ é igual à imagem do homomorfismo anterior $f_{p+1}$.

Um complexo de cadeias cujos grupos de homologia são iguais a zero em todas as dimensões é uma sequência exata.

Numa sequência exata, o homomorfismo $f_{p}$ é injetivo se, e somente se, $f_{p+1}=0$. Por sua vez, $f_{p+1}$ é sobrejetivo se, e somente se, $f_{p}=0$. Em particular, as sequências $0 \rightarrow M \stackrel{f}{\longrightarrow} N$ e $M \stackrel{g}{\longrightarrow} N \rightarrow 0$ são exatas se, e somente se, $f$ é injetivo e $g$ é sobrejetivo. Portanto, a sequência $0 \rightarrow M \stackrel{f}{\longrightarrow} N \rightarrow 0$ é exata se, e somente se, $f$ é um isomorfismo entre os A-módulos $M$ e $N$.

Definição 1.3.7. Uma sequência exata do tipo $0 \rightarrow M \stackrel{i}{\longrightarrow} N \stackrel{j}{\longrightarrow} P \rightarrow 0$ é chamada curta.

Neste caso, $i$ é injetivo, $j$ é sobrejetivo e $j^{-1}(0)=i(M)$. O exemplo típico de uma sequência exata curta é aquele em que $M$ é um submódulo de $N, i: M \rightarrow N$ é a inclusão, $P=N / M$ é o módulo quociente e $j: M \rightarrow P$ é a aplicação quociente.

Definição 1.3.8. Um morfismo entre duas sequências exatas $\left(M_{p}, f_{p}\right)$ e $\left(N_{p}, g_{p}\right)$ é uma sequência $\varphi_{p}: M_{p} \rightarrow N_{p}$ tais que $\varphi_{p-1} \circ f_{p}=g_{p} \circ \varphi_{p}$ para todo $p \geq 0$.

$$
\begin{array}{cl}
M_{p} \stackrel{f_{p}}{\longrightarrow} & M_{p-1} \\
\varphi_{p} \downarrow & \downarrow \varphi_{p-1} \\
N_{p} \stackrel{g_{p}}{\longrightarrow} & N_{p-1}
\end{array}
$$


Teorema 1.3.1. Num morfismo entre as sequências exatas de A-módulos,

$$
\begin{aligned}
& M_{5} \stackrel{f_{5}}{\longrightarrow} M_{4} \stackrel{f_{4}}{\longrightarrow} M_{3} \stackrel{f_{3}}{\longrightarrow} M_{2} \stackrel{f_{2}}{\longrightarrow} M_{1} \\
& \downarrow \varphi_{5} \quad \downarrow \varphi_{4} \quad \downarrow \varphi_{3} \quad \downarrow \varphi_{2} \quad \downarrow \varphi_{1} \\
& N_{5} \stackrel{g_{5}}{\longrightarrow} N_{4} \stackrel{g_{4}}{\longrightarrow} N_{3} \stackrel{g_{3}}{\longrightarrow} N_{2} \stackrel{g_{2}}{\longrightarrow} N_{1}
\end{aligned}
$$

se $\varphi_{1}, \varphi_{2}, \varphi_{4}$ e $\varphi_{5}$ são isomorfismos então $\varphi_{3}$ também é um isomorfismo.

Agora iremos mostrar a existência da sequência exata de homologia associada a uma sequência exata curta de morfismos entre complexos de cadeias.

Teorema 1.3.2. Seja $0 \rightarrow \mathcal{C}^{\prime} \stackrel{i}{\longrightarrow} \mathcal{C} \stackrel{j}{\longrightarrow} \mathcal{C}^{\prime \prime} \rightarrow 0$ uma sequência exata curta de morfismos entre complexos de cadeias. Existe, para cada $p \geq 0$, um homomorfismo $\partial_{*}: H_{p}\left(\mathcal{C}^{\prime \prime}\right) \rightarrow$ $H_{p-1}\left(\mathcal{C}^{\prime}\right)$ tal que a sequência

$$
\cdots \rightarrow H_{p}\left(\mathcal{C}^{\prime}\right) \stackrel{i_{*}}{\longrightarrow} H_{p}(\mathcal{C}) \stackrel{j_{*}}{\longrightarrow} H_{p}\left(\mathcal{C}^{\prime \prime}\right) \stackrel{\partial_{*}}{\longrightarrow} H_{p-1}\left(\mathcal{C}^{\prime}\right) \stackrel{i_{*}}{\longrightarrow} H_{p-1}(\mathcal{C}) \rightarrow \cdots
$$

é exata.

Há dois exemplos particularmente importantes de sequências exatas de homologia. O primeiro é quando se tem um subcomplexo $\mathcal{C}^{\prime} \subset \mathcal{C}$ e se toma $\mathcal{C}^{\prime \prime}=\mathcal{C} / \mathcal{C}^{\prime}$. Neste caso, $i: \mathcal{C}^{\prime} \rightarrow \mathcal{C}$ é a aplicação de inclusão e $j: \mathcal{C} \rightarrow \mathcal{C}^{\prime \prime}$ é a aplicação quociente. A sequência exata curta $0 \rightarrow \mathcal{C}^{\prime} \stackrel{i}{\longrightarrow} \mathcal{C} \stackrel{j}{\longrightarrow} \mathcal{C} / \mathcal{C}^{\prime} \rightarrow 0$ chama-se a sequência exata do par $\left(\mathcal{C}, \mathcal{C}^{\prime}\right)$ e os grupos de homologia $H_{p}\left(\mathcal{C} / \mathcal{C}^{\prime}\right)=H_{p}\left(\mathcal{C}^{\prime \prime}\right)$ chamam-se os grupos de homologia relativa do $\operatorname{par}\left(\mathcal{C}, \mathcal{C}^{\prime}\right)$.

O segundo exemplo é o da sequência de Mayer-Vietoris, que será muito importante para nosso estudo.

Para obter a sequência de Mayer-Vietoris, parte-se de dois subcomplexos $\mathcal{C}^{\prime}, \mathcal{C}^{\prime \prime} \subset \mathcal{C}$, tais que $\mathcal{C}=\mathcal{C}^{\prime}+\mathcal{C}^{\prime \prime}$, isto é, tem-se $C_{p}=C_{p}^{\prime}+C_{p}^{\prime \prime}$, para todo $p \geq 0$. Então os A-módulos $C_{p}^{\prime} \cap C_{p}^{\prime \prime}$, com o mesmo operador $\partial$ de $\mathcal{C}$, formam um complexo $\mathcal{C}^{\prime} \cap \mathcal{C}^{\prime \prime}$. Também as somas diretas $C_{p}=C_{p}^{\prime} \oplus C_{p}^{\prime \prime}$, cujos elementos escreveremos como pares $\left(x^{\prime}, x^{\prime \prime}\right) \operatorname{com} x^{\prime} \in C_{p}^{\prime} \mathrm{e}$ 
$x^{\prime \prime} \in C_{p}^{\prime \prime}$, munidas do operador $\partial: C_{p}^{\prime} \oplus C_{p}^{\prime \prime} \rightarrow C_{p-1}^{\prime} \oplus C_{p-1}^{\prime \prime}$, dado por $\partial\left(x^{\prime}, x^{\prime \prime}\right)=\left(\partial x^{\prime}, \partial x^{\prime \prime}\right)$, formam o complexo $\mathcal{C}^{\prime} \oplus \mathcal{C}^{\prime \prime}$, cujos grupos de homologia são $H_{p}\left(\mathcal{C}^{\prime} \oplus \mathcal{C}^{\prime \prime}\right) \approx H_{p}\left(\mathcal{C}^{\prime}\right) \oplus H_{p}\left(\mathcal{C}^{\prime \prime}\right)$.

Os morfismos $i: \mathcal{C}^{\prime} \cap \mathcal{C}^{\prime \prime} \rightarrow \mathcal{C}^{\prime} \oplus \mathcal{C}^{\prime \prime}$ e $j: \mathcal{C}^{\prime} \oplus \mathcal{C}^{\prime \prime} \rightarrow \mathcal{C}$, dados por $i(x)=(x, x)$ e $j(x, y)=x-y$, compõem a sequência curta

$$
0 \rightarrow \mathcal{C}^{\prime} \cap \mathcal{C}^{\prime \prime} \stackrel{i}{\longrightarrow} \mathcal{C}^{\prime} \oplus \mathcal{C}^{\prime \prime} \stackrel{j}{\longrightarrow} \mathcal{C} \rightarrow 0
$$

que é exata. E temos então a sequência de homologia

$$
\cdots \rightarrow H_{p}\left(\mathcal{C}^{\prime} \cap \mathcal{C}^{\prime \prime}\right) \stackrel{i_{*}}{\longrightarrow} H_{p}\left(\mathcal{C}^{\prime}\right) \oplus H_{p}\left(\mathcal{C}^{\prime \prime}\right) \stackrel{j_{*}}{\longrightarrow} H_{p}(\mathcal{C}) \stackrel{\Delta}{\longrightarrow} H_{p-1}\left(\mathcal{C}^{\prime} \cap \mathcal{C}^{\prime \prime}\right) \rightarrow \cdots
$$

chamada a sequência de Mayer-Vietoris do termo $\left(\mathcal{C}, \mathcal{C}^{\prime}, \mathcal{C}^{\prime \prime}\right)$. Nela, usamos a notação $\Delta$ em vez de $\partial_{*}$. Os homomorfismos $i_{*}$ e $j_{*}$ são óbvios: $i_{*}[z]=([z],[z])$ e $j_{*}([z],[w])=[z-w]$. Quanto a $\Delta$, tem-se $\Delta[z]=[\partial x]=[\partial y]$ onde $x-y=z, x \in C_{p}^{\prime}, y \in C_{p}^{\prime \prime}$ e $\partial x=\partial y$.

\subsection{Poliedros}

Definição 1.4.1. Pontos $a_{0}, a_{1}, \ldots, a_{r}$ são chamados pontos independentes quando os vetores $a_{1}-a_{0}, a_{2}-a_{0}, \ldots, a_{r}-a_{0}$ são linearmente independentes.

Definição 1.4.2. Uma combinação afim de pontos $a_{0}, a_{1}, \ldots, a_{r}$ em $\mathbb{R}^{n}$ é uma expressão do tipo $p=\alpha_{0} \cdot a_{0}+\alpha_{1} \cdot a_{1}+\ldots+\alpha_{r} \cdot a_{r}$ com $\alpha_{0}+\alpha_{1}+\ldots .+\alpha_{r}=1$. Se além disso tivermos $\alpha_{0} \geq 0, \alpha_{1} \geq 0, \ldots ., \alpha_{r} \geq 0$, diremos que p é uma combinação convexa dos $a_{0}, a_{1}, \ldots, a_{r}$.

Definição 1.4.3. Um conjunto $X \subset \mathbb{R}^{n}$ é convexo se, e somente se, toda combinação convexa de $X$ ainda pertence $a X$.

Definição 1.4.4. O conjunto de todas as combinações convexas de um conjunto $X$ é chamado de envoltória convexa de $X$.

Perceba então que a envoltória convexa é o menor conjunto convexo contendo X.

Definição 1.4.5. Sejam $a_{0}, a_{1}, \ldots, a_{r}$ pontos independentes em $\mathbb{R}^{n}$. O simplexo r-dimensional que tem estes pontos como vértices é o conjunto $s=\left\langle a_{0}, a_{1}, \ldots, a_{r}\right\rangle$ de todas as combinações convexas $p=\sum_{i=0}^{r} \alpha_{i} a_{i}$. 
Ou seja, O simplexo r-dimensional definido como acima é a envoltória convexa do conjunto $\left\{a_{0}, a_{1}, \ldots, a_{r}\right\}$.

Definição 1.4.6. Se $p=\sum_{i=0}^{r} \alpha_{i} a_{i} \in \operatorname{scom} \alpha_{0} \geq 0, \alpha_{1} \geq 0, \ldots ., \alpha_{r} \geq 0$, e $\alpha_{0}+\alpha_{1}+\ldots .+\alpha_{r}=$ 1 , os números $\alpha_{0}, \alpha_{1}, \ldots, \alpha_{r}$ são chamados de coordenadas baricêntricas do ponto $p$.

Definição 1.4.7. Se todas as coordenadas baricêntricas do ponto $p \in s$ são positivas, diz-se que p é um ponto interior de s. O conjunto dos pontos interiores é chamado um simplexo aberto. Os pontos de s que não são interiores formam o bordo de s.

Definição 1.4.8. Fixado um subconjunto $\left\{i_{0}, i_{1}, \ldots, i_{k}\right\} \subset\{0,1, \ldots, r\}$, o simplexo $\left\langle a_{i_{0}}, a_{i_{1}}\right.$, $\left.\ldots, a_{i_{k}}\right\rangle$ é chamado uma face de s. Para cada $i=0,1, \ldots, r$ a face $s_{(i)}=\left\langle a_{0}, a_{1}, \ldots, \widehat{a_{i}}, \ldots, a_{r}\right\rangle$ chama-se a face oposta ao vértice $a_{i}$.

Definição 1.4.9. Dado um conjunto convexo $C \subset \mathbb{R}^{n}$, diz-se que $p \in C$ é um ponto extremo de $C$ quando não pertence a segmento de reto aberto algum contido em $C$.

Teorema 1.4.1. Os pontos extremos do simplexo $s=\left\langle a_{0}, a_{1}, \ldots, a_{r}\right\rangle$ são os seus vértices.

Agora que já estudamos o conceito de simplexo podemos definir o seguinte:

Definição 1.4.10. Um complexo simplicial é um conjunto finito $K$ de simplexos em $\mathbb{R}^{n}$ com as seguintes propriedades:

1) Toda face de um simplexo de $K$ é ainda um simplexo de $K$;

2) Se s e t são simplexos de $K$ então $s \cap k$ é vazio ou é uma face comum a s e $t$.

Definição 1.4.11. A dimensão de um complexo simplicial é a maior dimensão de um dos seus simplexos.

Definição 1.4.12. O espaço subjacente de $K$, denotado por $|K|$, é o conjunto de pontos em $\mathbb{R}^{n}$ que pertence a pelo menos um simplexo de $K$. Isto é, $|K|$ é a união de simplexos de $K$.

\section{Exemplos:}

(1) Um grafo é um complexo simplicial de dimensão 1.

(2) O conjunto de todas as faces de um n-simplexo $s_{n}$ é um complexo simplicial de dimensão n. 
Definição 1.4.13. Um subcomplexo de um complexo simplicial $K$ é um subconjunto $L$ de $K$ que também é um complexo simplicial.

O subcomplexo é dito próprio se $L \neq K$.

Definição 1.4.14. Seja $r$ um inteiro $\geqslant 0$. O esqueleto $r$-dimensional de um complexo simplicial $K$ é o conjunto de todos os simplexos de $K$ com dimensão $\leqslant r$; denotaremos por $K^{r}$.

Perceba que o $K^{r}$ é um subcomplexo de $K$. E também que o esqueleto 1-dimensional $K^{1}$ de qualquer complexo simplicial é um grafo.

Definição 1.4.15. Um complexo simplicial $K$ é dito conexo se $K^{1}$ é um grafo conexo, i.e., existe um caminho de arestas de $K^{1}$ ligando quaisquer dois vértices.

Um subcojunto $U$ de $\mathbb{R}^{n}$ que é um espaço subjacente de algum complexo simplicial é também chamado de poliedro. A partir de agora iremos trabalhar com os poliedros ao invés de complexos simpliciais. De outra forma podemos definir um poliedro da seguinte maneira:

Definição 1.4.16. Um poliedro é um subconjunto $K \subset \mathbb{R}^{n}$, no qual foi especificada uma coleção finita de simplexos de $\mathbb{R}^{n}$, chamados os simplexos de $K$, satisfazendo as seguintes condições:

1) Todo ponto de $K$ pertence a algum simplexo de $K$;

2) Toda face de um simplexo de $K$ é ainda um simplexo de $K$;

3) Se s e $t$ são simplexos de $K$ então $s \cap k$ é vazio ou é uma face comum a s et.
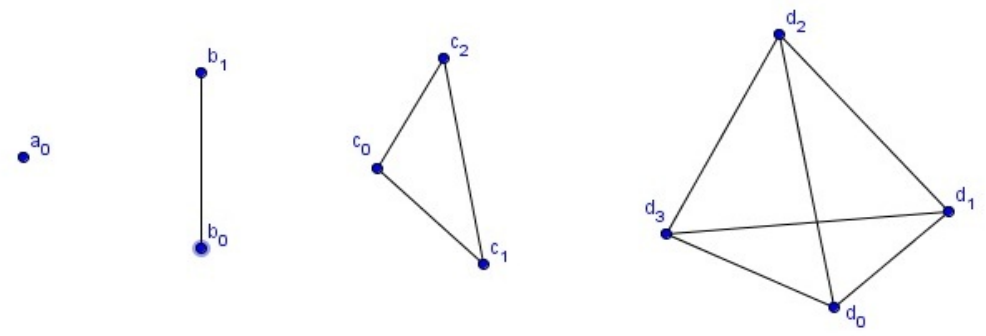

Figura 3: Exemplos de Poliedros.

Exemplo: O poliedro mais simples é um simplexo, juntamente com suas faces. Em dimensões $0,1,2$ e 3, ele é respectivamente um ponto, um segmento de reta, um triângulo 
ou um tetraedro (ver figura 3).

Todas as definições e propriedades de complexo simplicial como subcomplexo, esqueleto, dimensão valem para poliedros e é tudo definido de maneira análoga.

Definição 1.4.17. Uma aplicação $f: K \rightarrow L$ do poliedro $K$ no poliedro $L$ chama-se simplicial quando, para todo simplexo $s=\left\langle a_{0}, a_{1}, \ldots, a_{r}\right\rangle \in K$, as imagens $f\left(a_{0}\right), f\left(a_{1}\right), \ldots$, $f\left(a_{r}\right)$ são vértices de um mesmo simplexo $t \in L$ e, além disso, para todo $p=\sum \alpha_{i} \cdot a_{i}$ em $s$, tem-se $f(p)=\sum \alpha_{i} \cdot f\left(a_{i}\right) \in t$.

Toda aplicação simplicial é contínua pois K é uma reunião finita de conjuntos compactos, restrita a cada um dos quais f é contínua. A fim de definir uma aplicação simplicial $f: K \rightarrow L$ basta especificar a imagem $f(a)$ de cada vértice $a \in K$ contanto que, para todo simplexo $s=\left\langle a_{0}, a_{1}, \ldots, a_{r}\right\rangle \in K$, os pontos $f\left(a_{0}\right), f\left(a_{1}\right), \ldots, f\left(a_{r}\right)$ sejam vértices de um mesmo simplexo $t \in L$.

Por exemplo, se $K$ é o poliedro que se resume a um único simplexo $(\mathrm{n}+1)$-dimensional $s$, com suas faces, seu esqueleto n-dimensional $K^{n}$ é o bordo do simplexo $s$, portanto homeomorfo à esfera $S^{n}$. Isto mostra que $S^{n}$ é um espaço triangulável. Uma triangulação (homeomorfismo) $f: K^{n} \rightarrow S^{n}$ é por exemplo a projeção central a partir do baricentro de $s$.

Definição 1.4.18. Os poliedros $K$ e $L$ são isomorfos quando existem aplicações simpliciais $f: K \rightarrow L$ e $g: L \rightarrow k$ tais que $g \circ f=i d_{K}$ e $f \circ g=i d_{L}$. Então $f$ e $g$ são isomorfismos.

A fim de obter um isomorfismo entre os poliedros $K$ e $L$, basta estabelecer uma bijeção entre os vértices de $K$ e os de $L$, de tal modo que a vértices de $K$ pertencentes ao mesmo simplexo correspondam vértices de $L$ que também estão num mesmo simplexo.

Por isso um poliedro fica determinado (a menos de isomorfismo) pelo esquema simplicial por ele definido. 


\subsection{Homologia Simplicial}

Existem $(r+1)$ ! maneiras de ordenar os vértices de um simplexo de dimensão $r$. Iremos considerar duas ordenações equivalentes quando uma delas puder ser obtida por meio de uma permutação par dos $\mathrm{r}+1$ vértices. Há duas classes de equivalência segundo esta relação. Cada uma dessas classes chama-se uma orientação do simplexo. Orientar um simplexo é dotá-lo de uma dessas orientações possíveis. Escrevemos $s=\left[a_{0}, a_{1}, \ldots, a_{r}\right]$ para indicar o simplexo $s=\left\langle a_{0}, a_{1}, \ldots, a_{r}\right\rangle$ munido da orientação determinada pela ordem $a_{0}<a_{1}<\ldots<a_{r}$. O mesmo simplexo quando munido da orientação oposta seré indicado com -s.

Assim, por exemplo, se tomarmos no triângulo $s_{(0)}=\langle a, b, c\rangle$ a orientação $s=[a, b, c]$ (ver figura 4), a orientação oposta será $-s=[b, a, c]$. Note que $[a, b, c]=[c, a, b]=$ $[b, c, a]=-[a, c, b]=-[b, a, c]=-[c, b, a]$. Analogamente, as duas orientações possíveis do tetraedro $s_{(0)}=\langle a, b, c, d\rangle$ são $s=[a, b, c, d] \mathrm{e}-s=[b, a, c, d]$

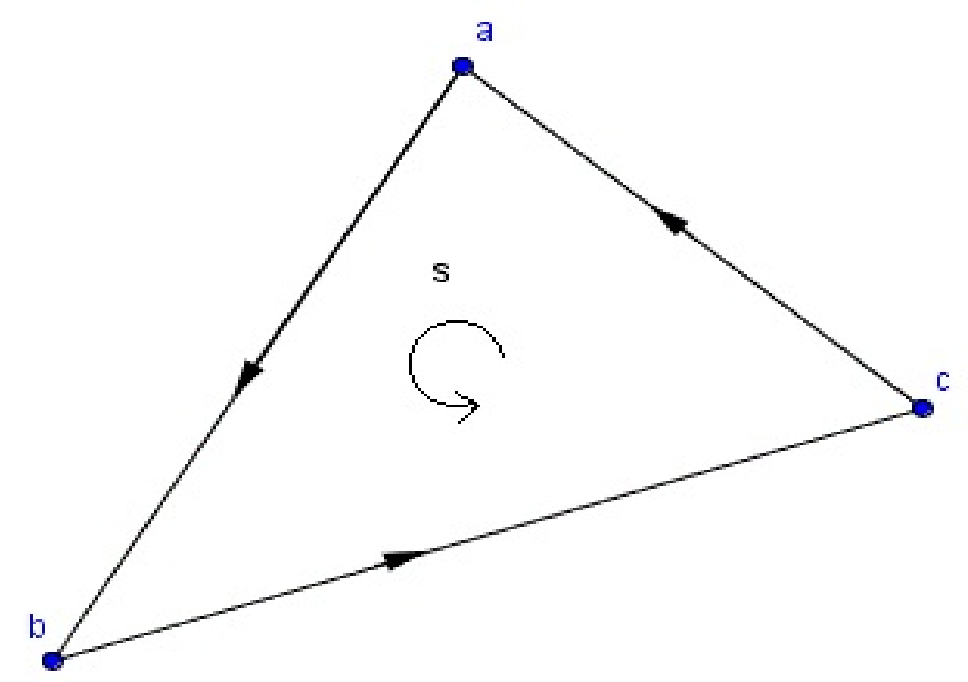

Figura 4: Triângulo orientado

Dado o simplexo orientado $s=\left[a_{0}, a_{1}, \ldots, a_{r}\right]$, a orientação induzida por s na face $s_{(0)}=\left\langle a_{1}, a_{2}, \ldots, a_{r}\right\rangle$, oposta ao vértice $a_{0}$, é $s_{(0)}=\left[a_{1}, a_{2}, \ldots, a_{r}\right]$

Quando orientarmos um simplexo r-dimensional, suas faces de dimensão r-1 herdam as orientações induzidas. O mesmo não se dá com as faces de dimensão r-2, conforme esclarece o teorema seguinte. 
Teorema 1.5.1. Num simplexo $r$-dimensional orientado s toda face (r-2)-dimensional $t$ pertence a duas faces de dimensão $r-1$, as quais, com as orientações nelas induzidas por $s$, induzem orientações opostas em $t$.

Dados os poliedros $\mathrm{K}$ e o anel comutativo com unidade A (anel dos coeficientes), consideramos, para cada inteiro $r \geq 0$, o A-módulo $C_{r}(K, A)$, que chamaremos de grupo e denotaremos por $C_{r}(K)$, salvo quando houver necessidade de sermos mais explícitos. Os elementos de $C_{r}(K)$, chamados cadeias $r$-dimensionais, são as combinações lineares formais $x=\sum x_{i} s_{i}$ de simplexos r-dimensionais orientados $s_{i} \in K$, com coeficientes $x_{i} \in A$.

Cada $C_{r}(K), r=0,1, \ldots$ é um A-módulo livre: escolhendo em cada r-simplexo $s \in K$ uma orientação, as r-cadeias $s$ assim obtidas formam uma base de $C_{r}(K)$.

A fim de definir o operador bordo $\partial: C_{r}(K) \rightarrow C_{r-1}(K)$ basta dar o significado de $\partial s$ para cada r-simplexo orientado s.

Poremos então $\partial s=\sum_{i=0}^{r} s_{(i)}$, onde $s_{(i)}$ é a i-ésima face de s com a orientação induzida.

Se $s=\left[a_{0}, a_{1}, \ldots, a_{r}\right]$ então $s_{(i)}=(-1)^{i}\left[a_{0}, \ldots, \widehat{a_{i}}, \ldots, a_{r}\right]$. Portanto

$$
\partial\left[a_{0}, a_{1}, \ldots, a_{r}\right]=\sum_{i=0}^{r}(-1)^{i}\left[a_{0}, \ldots, \widehat{a_{i}}, \ldots, a_{r}\right]
$$

Segue-se do Teorema 4.2 que $\partial \circ \partial=0$ e, se $\operatorname{dim} K=\mathrm{n}$, a sequência

$$
C(K): C_{n}(K) \stackrel{\partial}{\longrightarrow} C_{n-1}(K) \stackrel{\partial}{\longrightarrow} \ldots \stackrel{\partial}{\longrightarrow} C_{1}(K) \stackrel{\partial}{\longrightarrow} C_{0}(K) \rightarrow 0
$$

é um complexo de cadeias. Por completeza, pomos $\partial x=0$ para toda cadeia de dimensão $0, x=\sum x_{i} a_{i}$, combinação linear dos vértices $a_{i}$ do poliedro $K$. Mais geralmente, se $x=\sum x_{i} s_{i}$ é uma combinação linear dos r-simplexos orientados $s_{i} \in K$ com coeficientes $x_{i} \in A$, por definição tem-se $\partial x=\sum x_{i} \partial s_{i}$.

A partir de agora ao escrevermos $s=\left[a_{0}, a_{2}, \ldots, a_{r}\right]$ vamos permitir $a_{i}=a_{j} \operatorname{com} i \neq j$. Mas continuaremos impondo que se submetermos os vértices de $s$ a uma permutação ímpar, passa-se de $s$ a $-s$. Imporemos que $\left[a_{0}, a_{1}, \ldots, a_{r}\right]=0$ caso se tenha $a_{i}=a_{j}$ para 
$i \neq j$. Logo todo simplexo degenerado (com um ou mais vértices repetidos) é igual a zero.

É necessário mostrar que a definição de $\partial$ ainda vale mesmo com a imposição acima.

Com efeito, seja $s=\left[a_{0}, a_{1}, \ldots, a_{r}\right]$, onde $a_{i}=a_{j}(=b)$ com $0 \leq i<j \leq r$. Por definição, temos

$$
\partial s=\sum_{k=0}^{r}(-1)^{k}\left[a_{0}, \ldots, \widehat{a_{k}}, \ldots, a_{r}\right] .
$$

No somatório acima, exceto as parcela em que $\mathrm{k}=\mathrm{i}$ ou $\mathrm{k}=\mathrm{j}$, as demais correspondem a simplexos degenerados, logo são nulas. A soma reduz-se portanto a

$$
\begin{aligned}
& \partial s=(-1)^{i}\left[a_{0}, \ldots, a_{i-1}, a_{i+1}, \ldots, a_{j-1}, b, a_{j+1}, \ldots, a_{r}\right] \\
& +(-1)^{j}\left[a_{0}, \ldots, a_{i-1}, b, a_{i+1}, \ldots, a_{j-1}, a_{j+1}, \ldots, a_{r}\right]=0
\end{aligned}
$$

pois o segundo simplexo se transforma no primeiro fazendo b dar j-i-1 saltos, após cada um dos quais há uma mudança de sinal. No fim, a segunda parcela aparece com o coeficiente $(-1)^{j+j-i-1}=(-1)^{i+1}$, logo anula a primeira.

Temos assim associado a cada poliedro $K$ e cada anel comutativo com unidade $A$, o complexo de cadeias

$$
\mathcal{C}(K ; A)=\mathcal{C}(K): C_{n}(K) \stackrel{\partial}{\longrightarrow} C_{n-1}(K) \stackrel{\partial}{\longrightarrow} \cdots \stackrel{\partial}{\longrightarrow} C_{1}(K) \stackrel{\partial}{\longrightarrow} C_{0}(k) .
$$

Isto nos deixa em condições de utilizar todo o formalismo da teoria sobre homologia formal. Por exemplo, se $L \subset K$ é um subpoliedro, temos a homologia relativa $H_{r}(K ; L)$ com a respectiva sequência exata e, se $K=K_{1} \cup K_{2}$ em que $K_{1}$ e $K_{2}$ são subpoliedros, vale a sequência de Mayer-Vietoris correspondente.

Uma aplicação simplicial $f: K \rightarrow L$, do poliedro $K$ no poliedro $L$ induz um morfismo do complexo de cadeias $\mathcal{C}(K)$ em $\mathcal{C}(L)$, o qual indicamos com o mesmo símbolo f. Para cada $r \geq 0$, o homomorfismo $f: C_{r}(K) \rightarrow C_{r}(L)$ é definido, de modo natural pondo, para cada r-simplexo orientado $s=\left[a_{0}, \ldots, a_{r}\right] . f(s)=\left[f\left(a_{0}\right), \ldots, f\left(a_{r}\right)\right]$. Isto nos dá imediatamente $f(s)=0$ se $f\left(a_{i}\right)=f\left(a_{j}\right)$ com $i \neq j$. Além disso, vê-se facilmente que 
$f(\partial s)=\partial f(s), \operatorname{logo} f: \mathcal{C}(K) \rightarrow \mathcal{C}(L)$ é, de fato, um morfismo, o qual determina, em cada dimensão r, o homomorfismo $f_{*}: H_{r}(K) \rightarrow H_{r}(L)$, dado por $f_{*}([z])=[f(z)]$. Diz-se que $f_{*}$ é o homomor fismo induzido pela aplicação simplicial $f: K \rightarrow L$.

Se $f: K \rightarrow L$ e $g: L \rightarrow M$ são aplicações simpliciais então $g \circ f: K \rightarrow M$ também é simplicial e tem-se $(g \circ f)_{*}=g_{*} \circ f_{*}$. Além disso, como a aplicação identidade de $K$ em $K$ induz o homomorfismo identidade de $H_{r}(K)$ em $H_{r}(K)$, segue-se que um isomorfismo de poliedros $f: K \rightarrow L$ induz isomorfismos $f_{*}: H_{r}(M) \rightarrow H_{r}(L)$ em todas as dimensões.

\subsubsection{Exemplos de Homologia Simplicial}

Exemplo 1: A homologia de dimensão zero. Como o bordo de um vértice é zero, toda cadeia 0-dimensional $x=\sum x_{i} a_{i}$ no poliedro $K$ é um ciclo, ou seja $C_{0}(K)=Z_{0}(K)$. A fim de determinar o conjunto $B_{0}(K)$ dos bordos de dimensão 0, suporemos inicialmente que o poliedro $K$ seja conexo. Isto equivale a dizer que existe um caminho de arestas em $K$ ligando dois vértices quaisquer. Explicitamente: dados dois vértices arbitrários $a, b \in K$, existem vértices $a_{0}=a, a_{1}, \ldots, a_{m}=b$ em $K$ tais que $\left[a_{i-1}, a_{i}\right]$ é uma aresta (simplexo unidimensional) em $K$ para $i=1,2, \ldots, m$.

Dado o poliedro conexo $K$, definimos o homomorfismo $\operatorname{In}(x): C_{0}(K) \rightarrow A$ pondo, para cada 0 -cadeia $x=\sum x_{i} a_{i}$ em $K, \operatorname{In}(x)=\sum x_{i}$. O elemento $\operatorname{In}(x) \in A$ chama-se o indice de Kronecker de 0-cadeia $x$. Pois bem, a cadeia $x \in C_{0}(K)$ é um bordo se, e somente se, seu índice de Kronecer é igual a zero.

De fato, se existir $y \in C_{1}(K)$ tal que $\partial y=x$ então, escrevendo $y=\sum y_{i}\left[b_{i}, c_{i}\right]$ temos $\sum x_{i} a_{i}=x=\partial y=\sum y_{i} c_{i}-\sum y_{i} b_{i}$ portanto $\operatorname{In}(x)=\sum y_{i}-\sum y_{i}=0$. Reciprocamente, se a 0 -cadeia $x=\sum x_{i} a_{i}$ é tal que $\operatorname{In}(x)=\sum x_{i}=0$ então, fixando um vértice arbitrário $a \in K$, usamos a conexidade de $K$ a fim de obter, para cada $i$, um caminho de arestas em $K$ ligando $a$ e $a_{i}$, ou seja, uma 1-cadeia $c_{i}$ tal que $\partial c_{i}=a_{i}-a$. Então, considerando a 1-cadeia $y=\sum x_{i} c_{i}$ vemos que $\partial y=\sum x_{i} a_{i}-\left(\sum x_{i}\right) a=\sum x_{i} a_{i}=x$, portanto $x$ é um bordo.

O caso em que o poliedro $K$ não é conexo resulta de um fato mais geral: se $K=\bigcup_{i=1}^{m} K_{i}$ é a expressão de $K$ como reunião de suas componentes conexas (cada uma das quais 
é um poliedro, pois todo simplexo é conexo) então, para todo $r \geq 0$ tem-se $H_{r}(K)=$ $H_{r}\left(K_{1}\right) \oplus H_{r}\left(K_{2}\right) \oplus \cdots \oplus H_{r}\left(K_{m}\right)$, como se vê sem dificuldade. Em particular, tomando $r=0$ obtemos $H_{0}(K)=A^{m}$, onde $m$ é o número de componentes de $K$.

Exemplo 2: A homologia de um cone. Quando $t=\left\langle a, a_{0}, \ldots, a_{r}\right\rangle$ e $s=\left\langle a_{0}, \ldots, a_{r}\right\rangle$ é a face de $t$ oposta ao vértice $a$, escrevemos $t=a * s$. Se $a$ é um vértice do poliedro $K$, diz-se que $K$ é um cone de vértice a quando, para todo simplexo $s \in K$ que não tem a como vértice, $t=a * s$ é um simplexo de $K$. A reunião $L$ dos simplexos de $K$ dos quais $a$ não é vértice é um subpoliedro. Tem-se $K=\bigcup_{s \in L} a * s$, portanto é natural escrever $K=a * L$ e dizer que $L$ é a base do cone $K$ com vértice $a$. Um caso particular ocorre quando $L$ é um poliedro contido numa variedade afim $V \subset \mathbb{R}^{n}$ de dimensão $\leq n-1, a \notin V$ e $K=\bigcup_{s \in L} a * s$.

Seja $K$ um cone de vértice $a$. Como todo ponto de $K$ pode ser ligado a $a$ por um segmento de reta, $K$ é conexo, logo $H_{0}(K)=A$. Com o objetivo de calcular $H_{r}(K)$ com $r \geq 1$, consideremos a aplicação A-linear $a *: C_{r}(K) \rightarrow C_{r+1}$ definida pondo-se, para cada $s=\left[a_{0}, a_{1}, \ldots, a_{r}\right] \in C_{r}(K), a * s=\left[a, a_{0}, \ldots, a_{r}\right], \operatorname{logo} a * x=\sum x_{i} \cdot a * s_{i}$ quando $x=\sum x_{i} s_{i}$. Notemos que $a * s=0$ quando $a$ é um vértice do simplexo $s$.

Podemos verificar que, quando $s \in K$ tem dimensão $\geq 1, \partial(a * s)=s-a * \partial s$ para todo $s \in K$ e daí $\partial(a * x)=x-a * \partial x$ para toda cadeia $x \in C_{r}(K)$. Então, se $z \in Z_{r}(K)$ é um ciclo de dimensão $\geq 1$, tem-se $z=\partial(a * z)$. Portanto, quando $r \geq 1$, todo r-ciclo é um bordo, ou seja, $H_{r}(K)=0$.

Em particular, se $s$ é um simplexo, podemos considerá-lo como um cone em relação a qualquer dos seus vértices, portanto $H_{r}(s)=0$ se $r \geq 1$ e $H_{0}(s)=A$.

Exemplo 3: A homologia da esfera $S^{n}$. Seja $K$ o poliedro formado pelo simplexo $s=\left\langle a_{0}, a_{1}, \ldots, a_{n+1}\right\rangle$ e suas faces. A esfera $S^{n}$ é o esqueleto n-dimensional de $K$. Como $K$ é um cone (com vértice em qualquer um dos $a_{i}$ ) temos $H_{r}(K)=0$ para todo $r \geq 0$ e $H_{0}(K)=A$. Se $0<r<n$ tem-se também $H_{r}\left(S^{n}\right)=0$ pois, para esse valores de $r$, todo ciclo $z \in Z_{r}\left(S^{n}\right)=Z_{r}(K)$ é da forma $z=\partial x$, com $x \in C_{r+1}(K)=C_{r+1}\left(S^{n}\right)$. Resta determinar $H_{n}\left(S^{n}\right)$. A cadeia $z=\partial s$, soma de todas as n-faces de $S^{n}$ com as orientações induzidas por $s$, é certamente um n-ciclo em $S^{n}$, o qual não é bordo pois não há simplexos 
de dimensão $\mathrm{n}+1$ em $S^{n}$. Portando $[z] \neq 0$. Na verdade, $[z]$ é um gerador de $H_{n}\left(S^{n}\right)$ pois se tomarmos arbitrariamente um ciclo $w \in Z_{n}\left(S^{n}\right)=Z_{n}(K)$, como $H_{n}(K)=0$, existe $x \in C_{n+1}(K)$ tal que $\partial x=w$. Como $K$ tem apenas o simplexo $s$ em dimensão $\mathrm{n}+1$, temos $x=\alpha \cdot s, \alpha \in A, \operatorname{logo} w=\partial x=\alpha \cdot \partial s=\alpha \cdot z$. Portanto todo n-ciclo em $S^{n}$ é múltiplo de $z$ e daí $H_{n}\left(S^{n}\right)=A$.

Exemplo 4: A homologia do Anel Circular. O anel circular, subconjunto compacto do plano compreendido entre duas circunferências concêntricas, pode ser triangulado na forma da figura abaixo e assim é identificado a um poliedro bidimensional $K$ com 6 vértices.
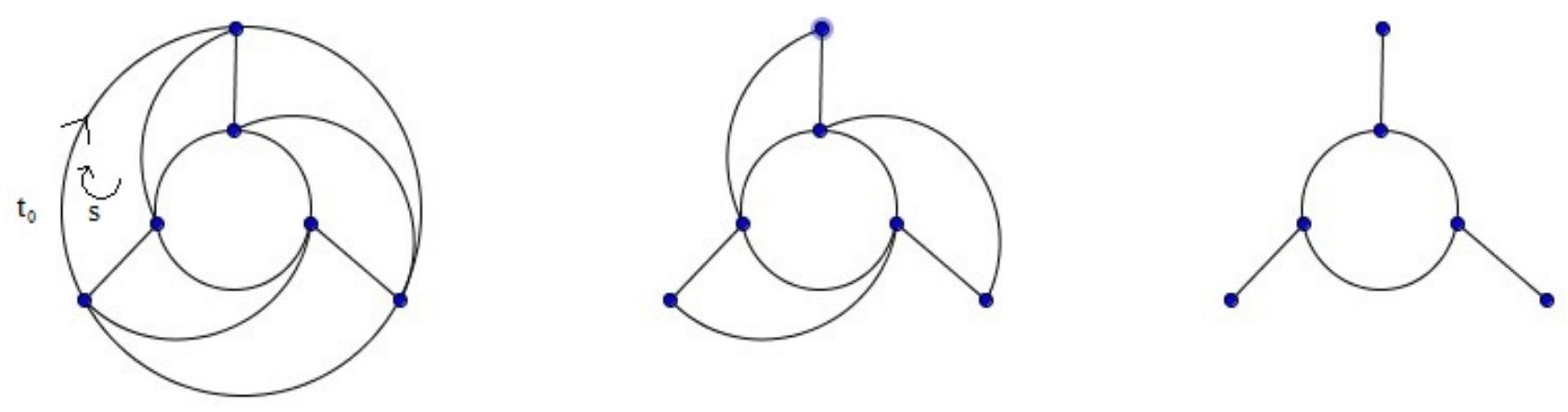

Figura 5

Como $K$ é conexo, temos $H_{0}(K)=A$. Para determinar $H_{1}(K)$, consideremos um ciclo $z=\sum x_{t} t \in Z_{1}(K)$. A soma estende-se a todas as arestas $t$ de $K$ e, para obtermos uma base de $C_{1}(K)$, fixamos arbitrariamente uma orientação em cada uma dessas arestas. Se alguma $t_{0}$ está situada na circunferência externa de $K$, ela é lado de um único triângulo S.

Ajustando a orientação de $\mathrm{s}$, vemos que $z^{\prime}=z-\partial\left(x_{t_{0}} \cdot s\right)$ é um ciclo homólogo a $z$, em cuja expressão $z^{\prime}=\sum m_{t} t$ a aresta $t_{0}$ aparece um coeficiente 0 . Repetindo este argumento, concluímos que todo ciclo $z \in Z_{1}(K)$ é homólogo a um $w \in Z_{1}(K)$ que é combinação linear de arestas, nenhuma das quais está sobre a circunfrência externa de $K$. Assim, $w$ é um ciclo do segundo poliedro da figura 5.

O mesmo tipo de raciocínio nos diz que $w$, por sua vez, é homólogo a um ciclo do terceiro poliedro da figura 5, o qual é, na realidade, um ciclo na circunferência interna 
(pois, do contrário, seu bordo conteria pelo menos um dos vértices salientes). Se chamarmos de $S^{1}$ a circunferência interna de $K$, vemos então que $H_{1}(K)=H_{1}\left(S^{1}\right)=A$. Resta mostrar que $H_{2}(K)=0$. A razão para isto é simplesmente que $Z_{2}(K)=0$, ou seja, não há 2-ciclos não nulos no poliedro $K$.

De fato, se atribuirmos a cada 2-simplexo de $K$ a orientação indicada na figura 6 e tivermos $z-\sum x_{s} \cdot s \in Z_{2}(K)$ então, como cada aresta de $K$ situada numa das duas circunferências da fronteira é face de apenas um triângulo, de $\partial z=0$ concluímos que $x_{s}=0$ para todo triângulo s que tenha um lado na fronteira, ou seja, para todo triângulo s. Portanto $z=0$. Assim os grupos de homologia do anel circular $K$, com coeficientes em $A$, são $H_{0}(K)=A, H_{1}(K)=A$ e $H_{2}(K)=0$.

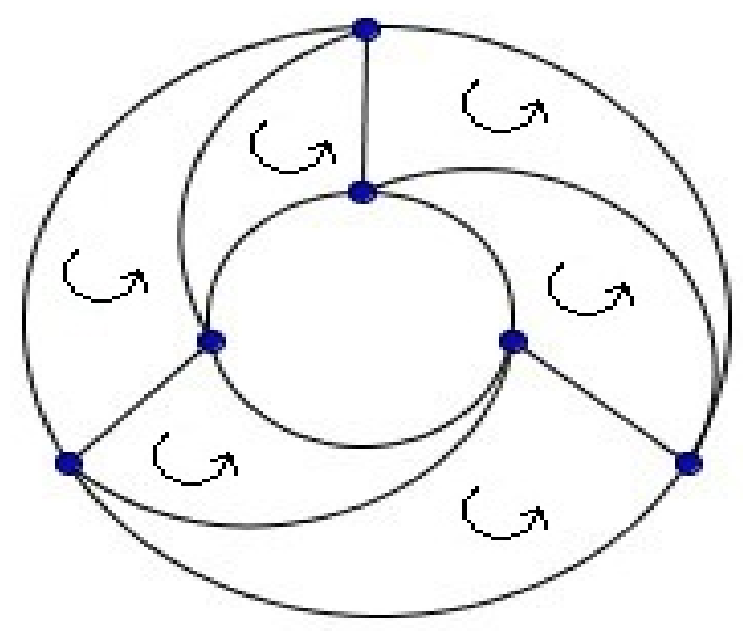

Figura 6

\subsection{Característica de Euler, Número de Betti e Genus}

Nesta seção iremos estabelecer uma conexão entre a Característica de Euler de um poliedro e os grupos de homologia desse poliedro. Devemos ressaltar que é possível definirmos a característica de Euler sem mencionar grupos de homologia, mas o único modo de falar sobre invariância topológica é usando a teoria de homologia.

Definição 1.6.1. Seja K um poliedro de dimensão n e L um subpoliedro de K. Seja $\alpha_{p}(K)$ e $\alpha_{p}(K, L)$ o número de simplexos p-dimensionais em $K$ e em $K \backslash L$ respectivamente. 
Então

$$
\mathcal{X}(K)=\sum_{p=0}^{n}(-1)^{p} \alpha_{p}(K) \text { e } \mathcal{X}(K, L)=\sum_{p=0}^{n}(-1)^{p} \alpha_{p}(K, L)
$$

é chamado de Característica de Euler (ou Euler-Poincaré) de $K$ e de $K \backslash L$ respectivamente.

Pensando no caso de superfícies trianguladas, podemos definir a Característica de Euler da seguinte maneira

$$
\mathcal{X}(K)=\alpha_{0}(K)-\alpha_{1}(K)+\alpha_{2}(K)
$$

em que $\alpha_{0}(K), \alpha_{1}(K)$ e $\alpha_{2}(K)$ são respectivamente o número de vértices, arestas e triângulos dessa triangulação.

Exemplo: [11] Para calcularmos a característica de Euler da esfera e do toro, considere as triangulações como na figura 7. Em $(i)$ temos um poliedro de dimensão $2 \mathrm{em} S^{2}$, sendo $\alpha_{0}=2, \alpha_{1}(K)=2$ e $\alpha_{2}=2$. Assim $\mathcal{X}\left(S^{2}\right)=2$. Em $(i i)$ temos um poliedro em $\mathbb{T}^{2}$. Neste caso $\alpha_{0}=4, \alpha_{1}(K)=8$ e $\alpha_{2}=4$. Assim $\mathcal{X}\left(\mathbb{T}^{2}\right)=0$.
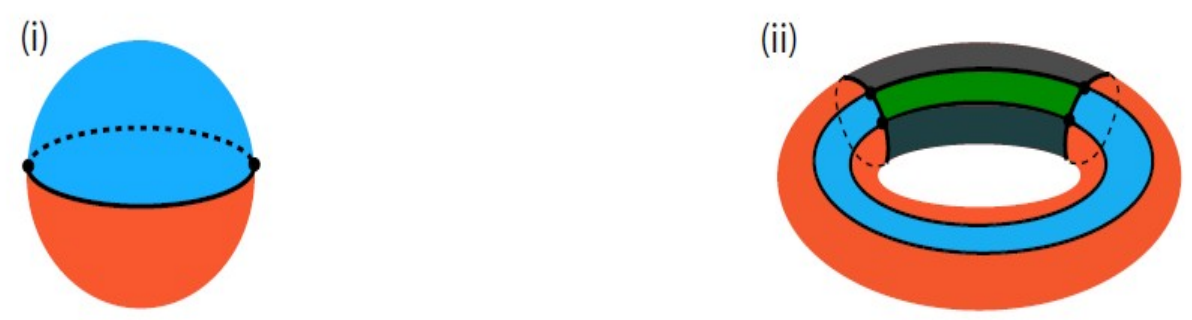

Figura 7: Esfera e Toro triangulados

A conexão entre a Característica de Euler e os grupos de Homologia do poliedro $K$ é dada no próximo teorema onde já assumimos que o poliedro $K$ acima é orientável.

Definição 1.6.2. Seja

$$
\beta_{p}(K)=\operatorname{dim}\left(H_{p}(K)\right) \text { e } \beta_{p}(K, L)=\operatorname{dim}\left(H_{p}(K, L)\right)
$$

Estes números são chamados de p-ésimos números de Betti de $K$ e de $K \backslash L$ respectiva- 
mente.

Teorema 1.6.1. [2]

$$
\mathcal{X}(K)=\sum_{p=0}^{n}(-1)^{p} \beta_{p}(K) \text { e } \mathcal{X}(K, L)=\sum_{p=0}^{n}(-1)^{p} \beta_{p}(K, L)
$$

Informalmente o k-ésimo número de Betti nada mais é que o número de superfícies k-dimensionais desconexas. Por exemplo podemos dar as seguintes definições intuitivas para os primeiros números de Betti:

- $b_{0}$ é o número de componentes conexas;

- $b_{1}$ é o número de buracos 2-dimensionais ou "circulares";

- $b_{2}$ é o número de buracos 3-dimensionais.

Exemplo: Um toro tem uma componente conexa, dois buracos circulares (um no centro e outro no meio do "tubo"), e um buraco 3-dimensional (dentro do "tubo"). Sendo assim, temos a seguinte sequência de números de Betti para o toro:

- $b_{0}=1$;

- $b_{1}=2$;

- $b_{2}=1$.

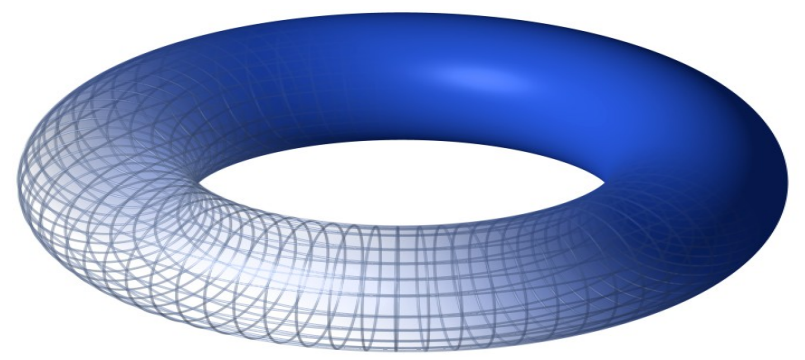

Figura 8: Toro.

\section{Exemplos:}

(i) A sequência dos números de Betti do círculo é 1,1,0,0,0...

(ii) A sequência dos números de Betti do bitoro é 1,2,1,0,0...

(iii) A sequência dos números de Betti do tritoro é 1,3,1,0... 
Agora iremos introduzir o conceito de genus de uma superfície pois este será usado como peso nas definições do grafo pesado e por isso serão muito importantes.

Definição 1.6.3. Uma superfície de genus p é uma variedade 2-dimensional homeomorfa ao espaço obtido removendo $2 p$ discos disjuntos de $S^{2}$ e adicionando $p$ cilindros disjuntos as suas fronteiras. (ver figura abaixo)

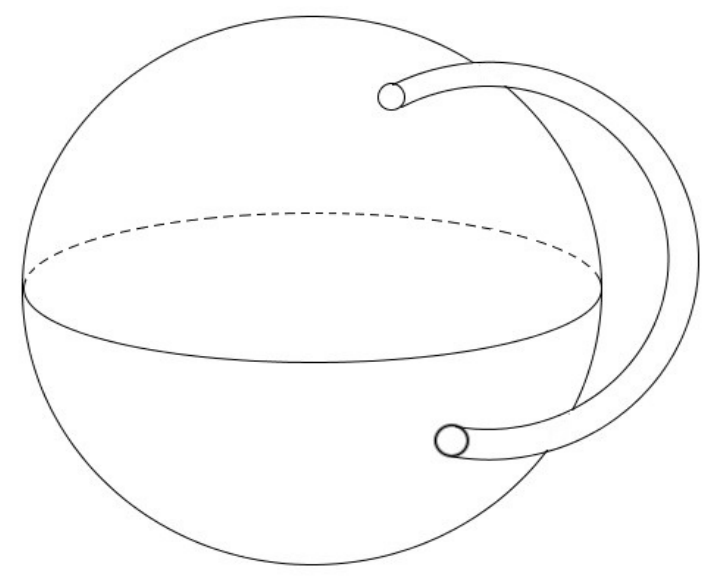

Figura 9: Superfície de genus 1

\section{Exemplos:}

(i) Como podemos perceber o toro é homeomorfo à figura acima. Portanto o genus do toro é igual à 1 .

(ii) Da mesma forma, um bitoro é homeomorfo a uma esfera com 4 círculos retirados e adicionando dois cilindros disjuntos. Assim o seu genus será igual à 2.

(iii) Da mesma forma, um tritoro tem genus 3. Seguindo com este raciocínio teremos que um n-toro terá genus igual à n. Dessa forma podemos ver de certa forma que o genus de superfície (orientável) é igual ao número de "buracos" que ela possui.

No nosso estudo trabalharemos frequentemente com superfícies com bordo e precisaremos da seguinte definição:

Definição 1.6.4. O genus de uma superfície com bordo é definido como o genus de uma superficie fechada obtida por adicionar um disco em cada componente de fronteira.

Exemplo: A semi-esfera com uma alça (ver figura 10) é uma superfície com bordo. Para calcular o seu genus, fechamos a "tampa" da esfera com um disco e teremos nova- 


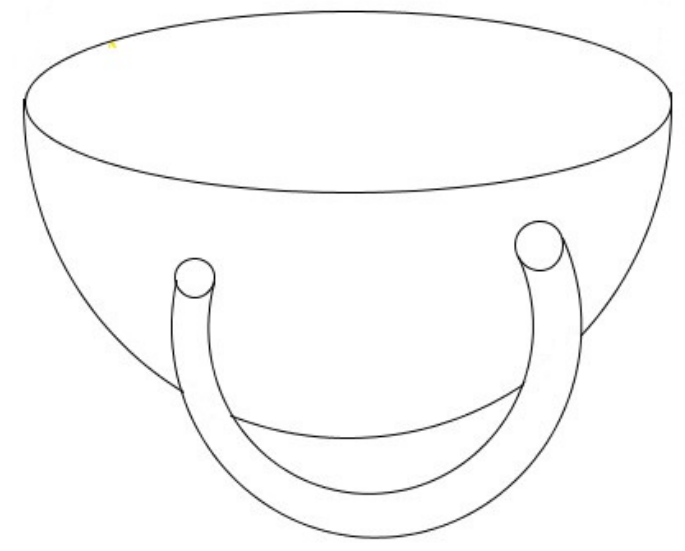

Figura 10: Superfície com bordo de genus 1

mente uma superfície homeomorfa à um toro. Portanto possuirá genus igual à 1 .

Neste trabalho teremos objetos um pouco mais complicados como na figura abaixo. Desta forma, precisaremos calcular o genus de cada uma das superfícies limitadas por curvas disjuntas imersas na superfície. Ou seja, obteremos superfícies com bordo onde as curvas que limitam as superfícies serão os bordos.

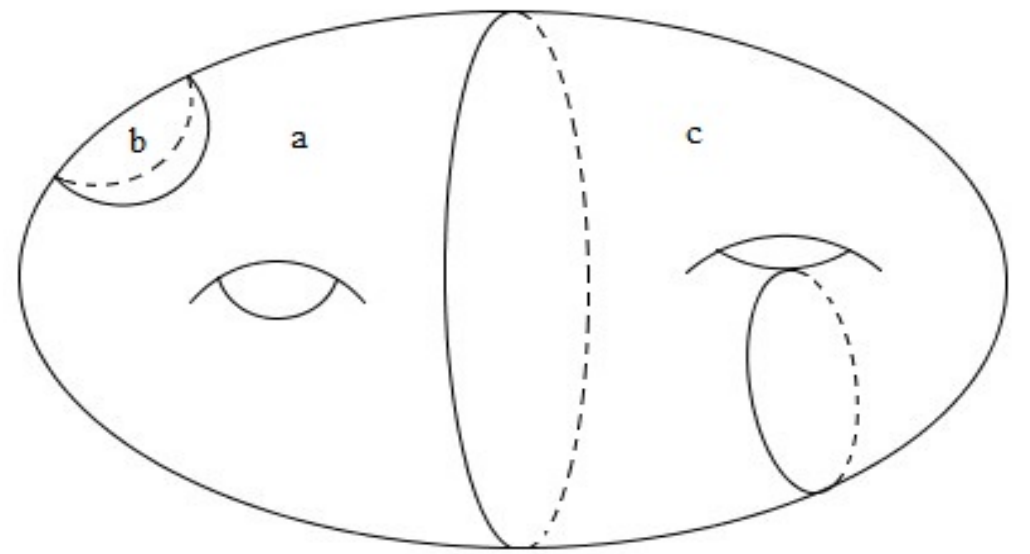

Figura 11: Superfícies com regiões limitadas por curvas de bordo

No exemplo da figura acima (ver figura 11) temos a seguinte configuração para as regiões delimitadas:

Região a: genus igual à 1, devido ao "buraco" contido nela.

Regiãa b: genus igual à 0 , pois após adicionarmos o disco ao bordo, a região $b$ será 
homeomorfa a uma esfera.

Região c: genus igual à 0 , pois após adicionarmos o disco ao bordo "tampamos" o buraco que a região possui.

Definição 1.6.5. A soma conexa de duas superfícies disjuntas $M_{1}$ e $M_{2}$ é dada pela remoção de um pequeno disco de cada uma delas, e unindo o bordo circular destes discos para formar uma nova superfície. Denotamos por $M_{1} \sharp M_{2}$ (ver figura abaixo)

Exemplo: A figura abaixo (ver figura 12) mostra claramente como é feita a construção da soma conexa entre um toro e um bitoro, desde a etapa de remoção do disco de cada uma das superfícies e a "colagem" delas formando um tritoro.

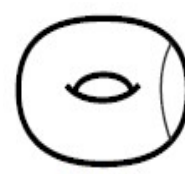

toro

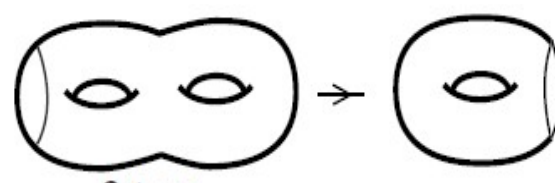

2-toro

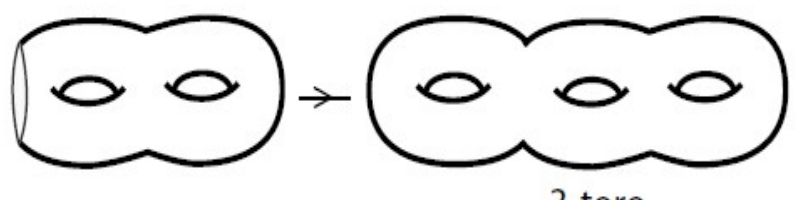

3-toro

Figura 12: Soma conexa entre um toro e um bitoro

Proposição 1.6.2. [11] Para a soma conexa de duas superfícies, $M_{1}$ e $M_{2}$, temos que

$$
\mathcal{X}\left(M_{1} \sharp M_{2}\right)=\mathcal{X}\left(M_{1}\right)+\mathcal{X}\left(M_{2}\right)-2 \text {. }
$$

Observação 3. Quando fazemos a soma conexa de uma superfície qualquer com uma esfera, não alteramos (a menos de homeomorfismo) a superfície. Ou seja, $M \sharp S^{2}=M$, para uma superfície $M$.

Teorema 1.6.3. [11] Uma superfície compacta, orientável e com bordo é homeomorfa à esfera ou à soma conexa de $n$ toros, com um número finito de discos removidos.

Teorema 1.6.4. [11] Seja $M$ uma superfície orientável sem bordo. A característica de Euler de $M$ é dada por

$$
\mathcal{X}(M)=2-2 g(M)
$$

onde $g(M)$ é o genus da superfície. 
Corolário 1.6.5. [11] Se $M$ é uma superfície orientável com $k$ componentes de bordo, então

$$
\mathcal{X}(M)=2-2 g(M)-k \text {. }
$$




\section{Capítulo}

\section{2}

\section{Grafos associados a coleções de curvas}

\section{fechadas em superfícies}

Neste capítulo associamos um par (superfície, família de curvas) com um grafo pesado. A seguir faremos o estudo em que essas curvas são o conjunto singular de uma aplicação estável de uma superfície no plano. Para isto, iniciaremos relembrando definições e propriedades importantes sobre aplicações estáveis de superfícies no plano.

\subsection{Aplicações estáveis de superfícies no plano}

Seja $f: \mathbb{R}^{2} \rightarrow \mathbb{R}^{2}$ uma aplicação estável. Então a forma normal de $f$ no ponto $(x, y)$ será uma das seguintes:

a) $f(x, y)=(x, y)$ regular;

b) $f(x, y)=\left(x, y^{2}\right)$ dobra;

c) $f(x, y)=\left(x, y^{3}+x y\right)$ cúspide.

Assim, se $f$ é estável, então suas singularidades serão dobras e cúspides (que aparecem em quantidade finita).

Na figura 13 podemos ver os pontos em verde no conjunto singular, formando as 


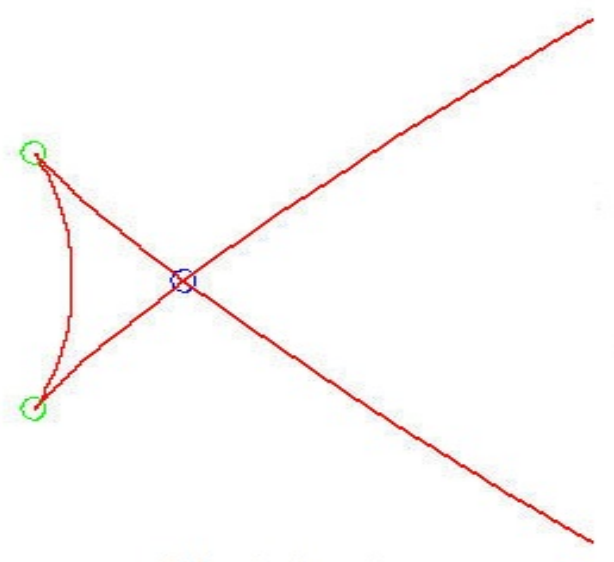

Discriminante

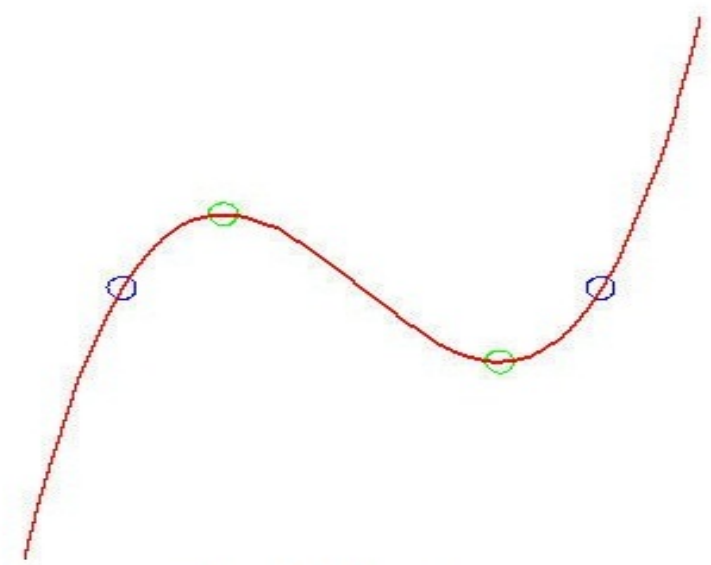

Conjunto Singular

Figura 13: Conjuntos discriminante e singular da aplicação $\left(x, y^{4}+x y^{2}-x y\right)$

cúspides no discriminante, e os pontos azuis formando o ponto duplo de dobra.

O conjunto singular de uma aplicação estável $f \in C^{\infty}\left(M, \mathbb{R}^{2}\right)$ consiste de uma quantidade finita de curvas fechadas mergulhadas e disjuntas de $M$. O conjunto discriminante consiste de um número finito de curvas planas imersas com cúspides, intersecções transversais e auto-intersecções (disjuntas do conjunto de cúspides).

Para estudarmos estes conjuntos singulares (conjuntos de curvas) usaremos as classes de isotopia correspondentes.

Definição 2.1.1. Sejam $P, Q$ variedades. Uma isotopia de $P$ em $Q$ é uma homotopia

$$
F: P \times I \rightarrow Q \quad, \quad F(x, t)=F_{t}(x)
$$

tal que a aplicação relacionada

$$
\hat{F}: P \times I \rightarrow Q \times I \quad, \quad \hat{F}(x, t)=\left(F_{t}(x), t\right)
$$

é um mergulho.

Chamamos $\hat{F}$ de caminho da função $F$. Também dizemos que $F$ é uma isotopia de $F_{0}$ em $F_{1}$. Ou seja, uma isotopia é uma família de 1-parâmetro suave $F_{t}$ de aplicações estáveis, 
$0 \leqslant t \leqslant 1$. Classes de isotopia correspondem a caminhos componentes de $\varepsilon\left(M, \mathbb{R}^{2}\right)$, o subespaço de $C^{\infty}\left(M, \mathbb{R}^{2}\right)$ consistindo de aplicações estáveis.

Isotopia implica equivalência, daí a importância de usarmos as classes de isotopoia. Mas o contrário não vale sempre.

Se $f$ e $g$ são funções isotópicas, então $\sum f$ e $\sum g$ são subconjuntos isotópicos de $M$ (i.e. existe um difeomorfismo de $\mathrm{M}$, que é isotópico à identidade e leva $\sum f$ em $\sum g$ ) e similarmente para $f\left(\sum f\right)$ e $f\left(\sum g\right)$. Assim qualquer invariante isotópico do conjunto singular ou do conjunto discriminante de $f$ será um invariante isotópico de $f$.

Na seção 2.2 iremos associar um grafo pesado à $\sum f$, cuja classe de isomorfismo é um invariante isotópico de $f$. Outro invariante global de $f$ que iremos considerar é o número de curvas de $\sum f$, denotado por $\mu$.

\subsection{Construção do grafo pesado}

O conjunto singular $\sum f$ é um invariante isotópico de aplicações estáveis. Portanto o número de componentes conexas de $\sum f$, bem como o tipo topológico de seu complemento em M também serão invariantes isotópicos. Daí a ideia de termos um grafo pesado onde toda essa informação será guardada. E a partir do grafo o par $M, \sum f$ poderá ser reconstruído (a menos de equivalência).

Explicaremos agora, dado uma superfície e uma coleção de curvas $\mathcal{C}$ mergulhadas disjuntas nela, como construir o grafo deste par $M, \mathcal{C}$.

O complemento em $M$ de uma coleção $C$ de curvas mergulhadas disjuntas é a união disjunta de regiões conexas. A fronteira de cada região consiste de um número finito de curvas (bordo). O grafo pesado $\mathcal{G}(M, C)$ é definido da seguinte forma: Existe um vértice para cada componente conexa de $M \backslash C$ e uma aresta para cada curva em $C$. Os dois (ou um) vértices de uma aresta correspondem as duas (ou uma) regiões que tem como parte de seu bordo a curva da aresta em questão. Ressaltamos que podem ocorrer loops. Por exemplo, o grafo correspondente a uma superfície com uma única curva que não separa 
a superfície em mais de uma região diferente terá um vértice e uma aresta (ver Exemplo 1 abaixo). Cada vértice do grafo terá um peso que será dado pelo genus da região da superfície correspondente a este vértice no grafo (basta lembrar a definição de genus de uma superfície fechadada dada nas preliminares).

Exemplo 1: Toro com uma curva $f$ que não o separa em mais de uma região. O seu grafo será apenas um loop ligando o vértice correspondente a única região a nele mesmo (ver figura 14).

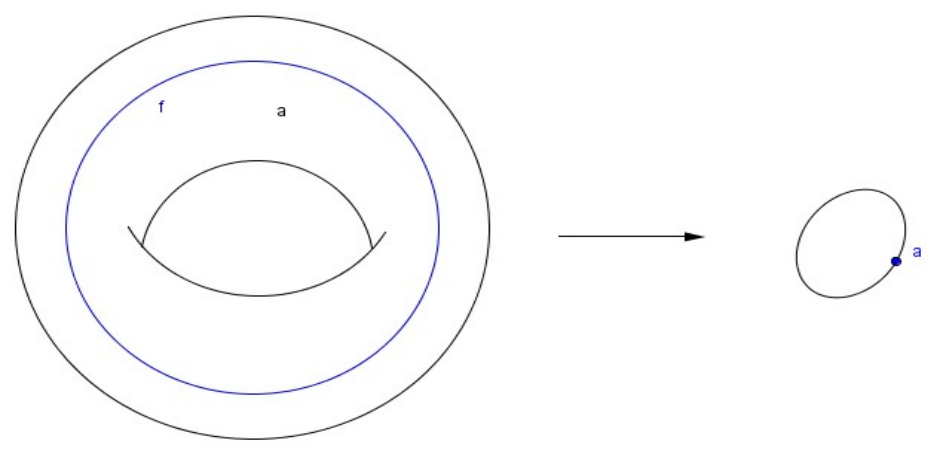

Figura 14

Exemplo 2: Considere agora a superfície com uma família de curvas dada na figura 11, página 28 no Capítulo 1. Lá já foi calculado o genus de cada região. O seu grafo correspondente terá 3 vértices (um para cada região) com pesos dados pelo genus da região (ver figura 15).

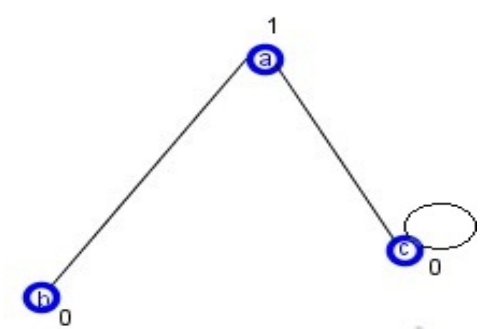

Figura 15: Grafo da superfície dada na figura 11, página 28.

Exemplo 3: E da mesma forma podemos tomar uma superfíce com um maior número de curvas, como na figura 16. 


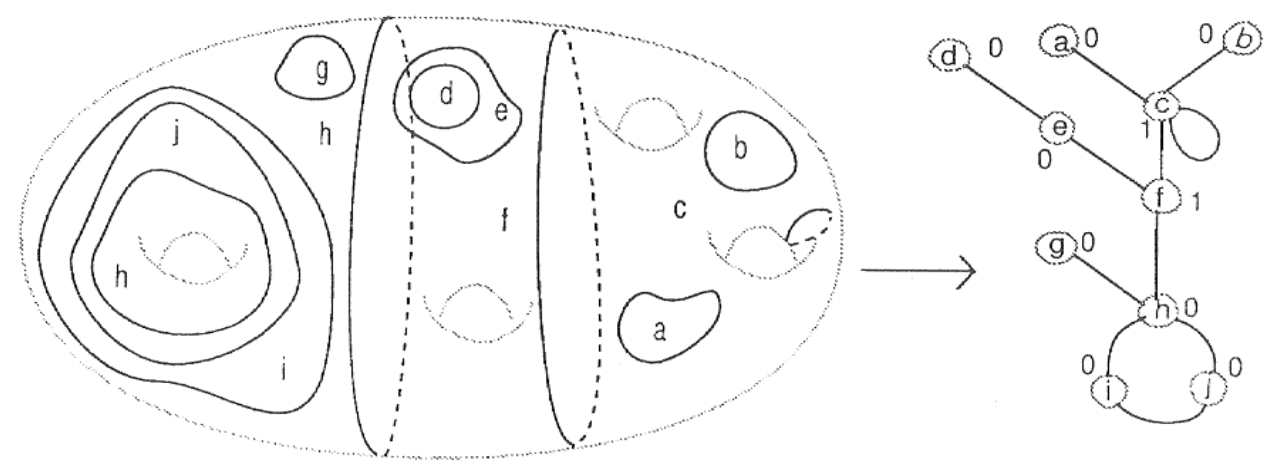

Figura 16: Superfície com uma família de curvas imersas e seu grafo.

Dois conjuntos de curvas $C$ e $C^{\prime}$ em uma superfície $M$ são ditos isotópicos se existe uma isotopia de $M$ que leva $C$ em $C^{\prime}$. Isto implica que existe um difeomorfismo de $M$ levando $C$ em $C^{\prime}$. Se $C$ e $C^{\prime}$ são conjuntos de curvas em $M$ e $M^{\prime}$ respectivamente, então dizemos que os pares $M, C$ e $M^{\prime}, C^{\prime}$ são equivalentes se existe um difeomorfismo entre $M$ e $M^{\prime}$ levando $C$ em $C^{\prime}$. Claramente, pares equivalentes tem grafos com peso isomorfos (isomorfismo de grafos preservam pesos). Na verdade define-se uma bijeção entre classes de equivalência de pares e isomorfismos de grafos com peso.

Teorema 2.2.1. Todo grafo pesado é isomorfo ao grafo de um par $M, C$ e este par é único a menos de equivalência. O genus $g(M)$ é dado por

$$
g(M)=\alpha-\nu+1+\sum g(v)
$$

em que a é o número de arestas, $\nu$ o número de vértices e $\sum$ representa a somatória dos pesos de todos os vertices do grafo.

Demonstração.: Inicialmente mergulhamos o grafo em um 3-espaço e seja $M_{0}$ a fronteira de uma vizinhança tubular adequada do grafo, com curvas definidas de maneira óbvia, uma para cada aresta.

Assim obtemos um par $\left(M_{0}, \mathcal{C}\right)$ que tem como grafo correspondente $\mathcal{G}$, mas com todos os pesos iguais à zero. Note que para cada vértice de $\mathcal{G}$ está associado naturalmente uma região do complemento $M_{0}-\mathcal{C}$. Podemos observar também que o genus de $M_{0}$ corresponde ao número de ciclos de $\mathcal{G}$. 
$M$ é então a soma conexa de $M_{0}$ com superfícies de genus apropriado: para cada vértice $v$ fazemos a soma conexa da região $M_{0}$ correspondente a $v$ com uma superfície fechada de genus $g(v)$.

O grafo pesado do par $M, C$ é o grafo original.

Por outro lado, dado um par $M, C$, ele pode ser visto como a soma conexa de uma par W,C com superfícies de genus $\mathrm{g}(\mathrm{v})$, um para cada vértice.

Os dois pares tem o mesmo grafo, mas W,C tem todos pesos iguais a zero. A superfície $\mathrm{W}$, sendo orientável, é difeomorfa a bordo de uma vizinhança apropriada do grafo mergulhado no 3-espaço.

Pela unicidade da soma conexa, o par $M, C$ é equivalente ao par obtido reconstruindo o grafo como antes. Da descrição anterior do par como uma soma conexa, o genus de M é a soma $\sum_{v} g(v)$ e o genus de $M_{0}$. Mas o último é $\alpha-\nu+1$.

A construção feita acima nos mostra como sair de um grafo pesado e chegar na superfície com a família de curvas que correspondem a este grafo. Esta construção pode ser melhor visualizada no exemplo da figura abaixo (ver [11]):

(a)

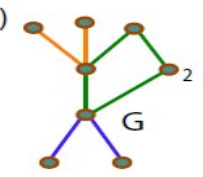

(f)

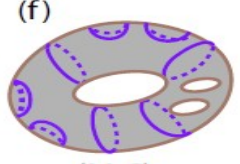

$(\mathrm{M}, \mathrm{C})$
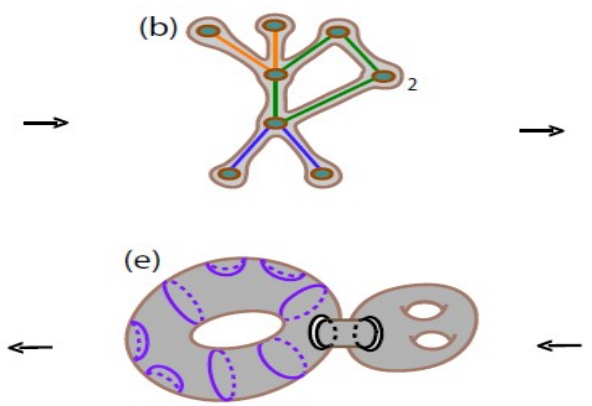

(c)

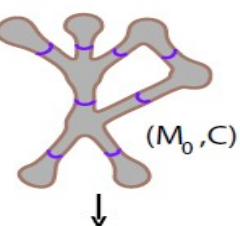

(d)

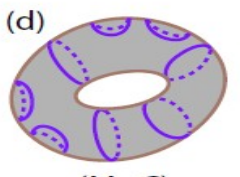

$\left(M_{0}, C\right)$

Figura 17: Realização do Grafo Pesado em uma Superfície com uma família de Curvas

Uma consequência imediata disto é:

Corolário 2.2.2. Para qualquer par $M, \mathcal{C}$ a superfície $M$ é uma esfera se e somente se o grafo pesado associado é uma árvore com todos os pesos iguais à zero. 
Demonstração: Como $M$ é uma esfera, então $g(M)=0$. Mas dada qualquer coleção de curvas disjuntas em uma esfera temos que $\alpha-\nu=-1$. Pelo teorema acima temos que

$$
g(M)=\alpha-\nu+1+\sum g(v)
$$

Portanto $\sum g(v)=0$. Reciprocamente se $G$ é uma árvore com todos os pesos iguais a zero então $\alpha-\nu+1=0$ pois não possui loops (lembrando que $\alpha-\nu+1$ é o número ciclomático de um grafo (ver Definição 1.2.10)) e $\sum g(v)=0$. Então $g(M)=0$. Então $M$ é uma esfera.

Observamos que o caso da esfera é especial uma vez que dois conjuntos de curvas na esfera são isotópicos se e somente se são equivalentes. A razão disto é que qualquer par M,C pode ser levado nele mesmo por um difeomorfismo que reverte a orientação. No entanto, se um difeomorfismo da esfera levando um conjunto de curvas em outro conjunto de curvas reverte a orientação, este pode ser substituído por um difeomorfismo que preserva orientação e então será isotópico à identidade. Logo os dois conjuntos de curvas são isotópicos na esfera. Para superfícies de genus maior, isotopia e equivalência são condições diferentes. 


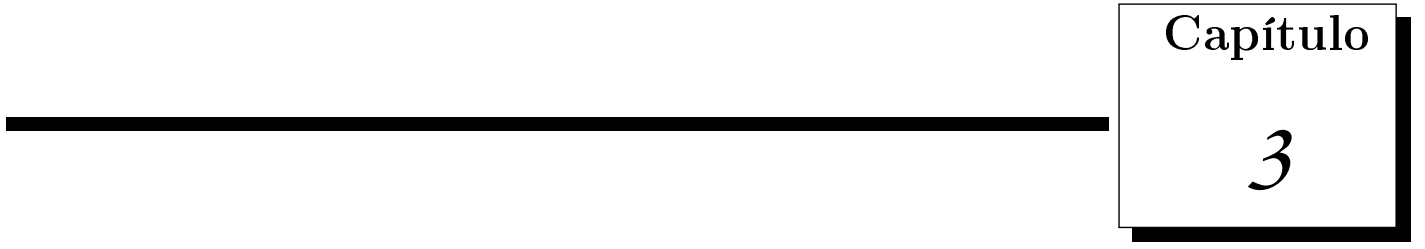 \\ Grafos de aplicações estáveis de uma superfície no plano}

Dada qualquer aplicação estável $\mathrm{f}$ teremos um grafo pesado $\mathcal{G}(M, C)$ associado a esta aplicação. Claramente aplicações estáveis equivalentes possuem grafos pesados isomorfos.

Uma questão natural é:

"Quais conjuntos de curvas podem ser vistos como conjuntos singulares de aplicações estáveis?"

No caso da esfera, qualquer conjunto de curvas não vazio será um conjunto singular se permite cúspides (se cúspides não são permitidas, então a questão parece ser bem mais difícil de responder). Relembre que para M ser uma esfera o grafo precisa ser uma árvore com todos os pesos iguais a zero. Uma árvore com uma aresta claramente pode ser vista como projeção ortogonal de uma esfera no plano. Agora considere uma árvore T com mais de duas arestas. Escolha uma aresta nos extremos (i.e. uma que encontra o resto da árvore em somente um vértice, digamos v). Por indução, a árvore menos esta aresta pode dar origem a um conjunto singular. Dentro da região correspondente ao vértice v criamos um par de cúspides dando origem a uma curva-dobra (contendo as duas cúspides), delimitando um disco que é mapeado em uma região em forma de lábio no plano. Isto nos da a árvore $\mathrm{T}$.

Consequentemente temos o seguinte 
Teorema 3.0.3. [4] Qualquer árvore com todos pesos iguais a zero dão origem a um grafo de uma aplicação estável da esfera no plano.

Para a questão de dar origem a grafos por aplicações simples (i.e. aplicações que não possuem cúspides) temos os seguintes exemplos. Primeiro, é claro que se T é uma árvore gerada por um aplicação estável simples da esfera no plano, então a árvore obtida adicionando uma árvore de duas arestas a $\mathrm{T}$ no vértice $\mathrm{v}$ de $\mathrm{T}$ pode ser similarmente realizada. Modifique f dentro de um disco pequeno contendo a região correspondente a v introduzindo duas curvas dobras paralelas (sem cúspides). Isto tem o efeito de adicionar uma árvore de duas arestas em v. Claramente, qualquer árvore com todos pesos iguais a zero e que pode ser obtida através de uma árvore de uma aresta adicionando sucessivamente árvores com duas arestas como anteriormente podem ser geradas sem cúspides.

Uma segunda classe de exemplos pode ser construída por projeções ortogonais de superfícies adequadas mergulhadas em um 3-espaço. Um simples exemplo com pesos 1 e 1 é dado por uma aplicação de uma superfície de genus par com exatamente uma curva dobra simples, como mostrado na figura abaixo.
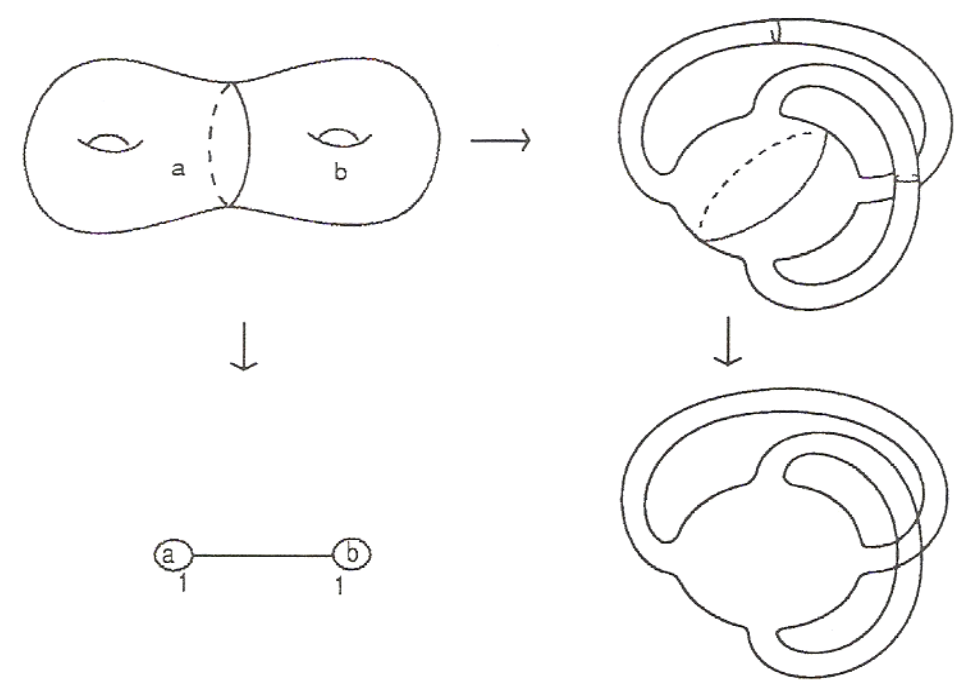

Figura 18 


\section{Capítulo}

\section{Grafos associados à superfícies em uma}

3-variedade

\subsection{Aplicações estáveis de 3-variedades em $\mathbb{R}^{3}$}

Começaremos relembrando algumas definições básicas e resultados sobre aplicações estáveis de 3 -variedades em $\mathbb{R}^{3}$. Os reultados citados aqui são de [9], [10] e [3].

Relembrando e adaptando algumas definições da seção 1.1 temos que duas aplicações suaves $f$ e $g$ de uma 3 -variedade $M$ em um 3-espaço são chamadas $\mathcal{A}$-equivalentes se existem difeomorfismos, $l$ e $k$, tais que $l \circ f=g \circ k$. Uma aplicação suave $f$ é dita estável se todas as aplicações suficientemente próximas à $f$ (na topologia $C^{\infty}$ de Whitney) são $\mathcal{A}$ - equivalentes à f. O conjunto singular $\sum f$ de uma aplicação estável $f$ consiste de superfícies disjuntas mergulhadas. Cada superfície consiste de pontos de dobra juntos com curvas de pontos de cúspide (i.e. pontos cuja a imagem é um ponto de cúspide do conjunto discriminante $f\left(\sum f\right)$ ) onde podem existir pontos de rabo de andorinha isolados. A seguir temos as formas normais dos germes desses pontos singulares:

a) $f(x, y, z)=\left(x, y, z^{2}\right)$ ponto de dobra, 
b) $f(x, y, z)=\left(x, y, z^{3}+x z\right)$ ponto de cúspide,

c) $f(x, y, z)=\left(x, y, z^{4}+x z+y z^{2}\right)$ ponto de rabo de andorinha.

Por outro lado, o conjunto discriminante de uma aplicação estável pode ter autointersecções das seguintes formas:

a) cruzamento transversal de superfícies dobra (ao longo de curvas regulares),

b) intersecção transversal de uma aresta cuspidal com uma superfície dobra (em pontos isolados),

c) pontos triplos isolados obtidos pela intersecção de superfícies dobra em posição geral.

A figura 19 nos mostra todas as possibilidades para a geometria local do conjunto singular e do conjunto discriminante de uma aplicação estável. Os pontos vermelhos são eixos cuspidais, os pontos azuis são uma curva de pontos duplos. O ponto $A_{1,2}$ representa um cruzamento de um eixo cuspidal com a curva de pontos duplos. O ponto $A_{3}$ representa um rabo de andorinha. O $A_{1,1,1}$ é um ponto triplo. E o $A_{1}$ representa os pontos de dobra.

Se $f$ e $g$ são $\mathcal{A}$ - equivalentes então existe um difeomorfismo da 3-variedade levando o conjunto singular de $f$ no conjunto singular de $g$ e similarmente para os conjuntos discriminantes de $f$ e de $g$. Claramente, qualquer invariante por difeomorfismo do conjunto singular ou do conjunto discriminante será um $\mathcal{A}$ - invariante de $f$. O número de componentes conexas do conjunto singular e o tipo topológico do seu complemento são invariantes.

\subsection{3-variedades e grafos}

Nesta seção iniciaremos o estudo dos grafos dos pares formados por uma 3variedade e uma família de superfícies mergulhadas nessa 3-variedade. Para este estudo foi usado [9] e [10]. 


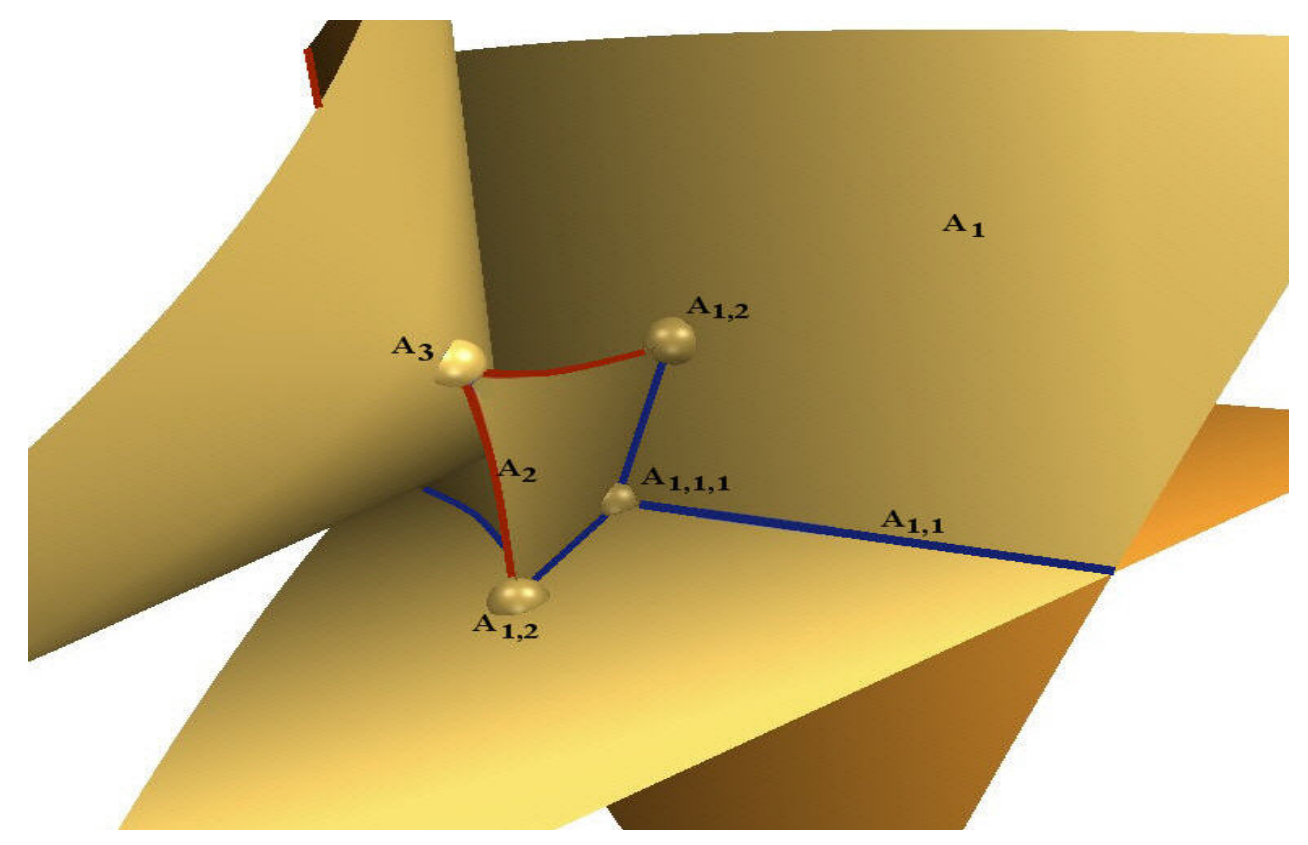

Figura 19: Geometria local do Conjunto Discriminante de uma Aplicação Estável

Vamos começar com algumas informações básicas sobre 3-variedades. Seja $M$ uma 3-variedade com bordo compacta, conexa e orientável. E seja $b_{i}=\operatorname{dim}\left(H_{i}(M)\right)$ o i-ésimo número de Betti de $M$. Perceba que $b_{0}=b_{3}=1$. Por outro lado, temos pela desigualdade de Poincaré que $b_{1}=b_{2}$. Então $\mathcal{X}(M)=0$, onde $\mathcal{X}$ é a característica de Euler, pois $\mathcal{X}(M)=\sum_{i=0}^{3}(-1)^{i} b_{i}$.

Seja $\bigcup_{i=1}^{n} S_{i} \subset M$ uma coleção de superfícies mergulhadas orientadas disjuntas em uma 3 -variedade compacta. Definimos o grafo pesado $\mathcal{G}$ associado a esta coleção de superfícies em $M$ como segue: associamos a cada superdície $S_{i}$ uma aresta e a cada componente $M_{j}$ de $M-\bigcup_{i=1}^{n} S_{i}$ um vértice. Então temos que uma aresta está ligada a um vértice se e somente se a superfície correspondente à aresta está no bordo da 3-variedade representada pelo vértice. Os pesos são definidos da seguinte forma: dado um vértice $v_{j}$ (correspondente a região $M_{j}$ ) definimos seu peso como $c_{j}=b_{2}\left(M_{j}\right)-s_{j}+1$, em que $s_{j}$ é o número de componentes conexas do bordo de $M_{j}$. Intuitivamente, $c_{j}$ pode ser visto como o número de geradores de $H_{2}(M)$ em $M_{j}$ que não são determinados pelo bordo de $M_{j}$. E para cada aresta associamos o peso dado pelo genus, $g_{i}$, da superfície $S_{i}$ que ele representa. 
Chamaremos de $\mu$ o número de arestas (que é o número de superfícies $S_{i}$ ) do grafo e de $V$ o número de vértices.

Proposição 4.2.1. Se $M=S^{3}$ então $c_{j}=0$, para todo $j$.

Demonstração: Considere $M_{s}$ a variedade obtida de $S^{3}$ após a remoção do interior de $s$ superfícies sólidas e seja $\bigcup_{i=0}^{s} S_{i}$ a união dos bordos das superfícies sólidas, i.e., o bordo da 3 -variedade resultante $M_{1}$. Para calcularmos o segundo número de Betti de $M_{1}$, consideramos $M_{2}$ a união das superfícies sólidas.

Temos então que $M_{1} \cap M_{2}=\bigcup_{i=0}^{s} S_{i}$ e $M_{1} \cup M_{2}=S^{3}$. Considere agora a sequência exata de Mayer-Vietoris para esta partição de $S^{3}$ :

$$
\begin{aligned}
& \ldots \rightarrow H_{3}\left(M_{1}\right) \oplus H_{3}\left(M_{2}\right) \stackrel{h_{*}}{\longrightarrow} H_{3}\left(S^{3}\right) \stackrel{\Delta_{2}}{\longrightarrow} H_{2}\left(M_{1} \cap M_{2}\right) \ldots \\
& \stackrel{g_{*}}{\longrightarrow} H_{2}\left(M_{1}\right) \oplus H_{2}\left(M_{2}\right) \stackrel{h_{*}}{\longrightarrow} H_{2}\left(S^{3}\right) \stackrel{\Delta_{1}}{\longrightarrow} H_{1}\left(M_{1} \cap M_{2}\right) \ldots
\end{aligned}
$$

Substituindo na sequência a informação que temos, obtemos a seguinte sequência:

$$
\ldots \rightarrow 0 \oplus 0 \stackrel{h_{*}}{\longrightarrow} \mathbb{Z} \stackrel{\Delta_{2}}{\longrightarrow} \mathbb{Z}^{s} \stackrel{g_{*}}{\longrightarrow} \mathbb{Z}^{b_{2}\left(M_{1}\right)} \oplus 0 \stackrel{h_{*}}{\longrightarrow} 0 \rightarrow \ldots
$$

Usando o primeiro teorema do isomorfismo e fato de que a sequência é exata temos que $b_{2}\left(M_{1}\right)=s-1$.

Relembrando o capítulo 1, um grafo é dito bipartido se seus vértices podem ser indexados com sinais \pm de tal forma que 2 vértices de uma aresta qualquer possuem sinais opostos. Isto é equivalente a pedir que qualquer loop no grafo seja composto por um número par de arestas. Percebe-se que qualquer árvore (grafos sem loops) é um grafo bipartido.

Existem algumas consequências imediatas que podem ser tiradas da forma que definimos o grafo. Seja $\bigcup_{i=1}^{\mu} S_{i} \subset M$ uma coleção de superfícies mergulhadas fechadas disjuntas na variedade. O complemento desta coleção de superfícies é uma coleção de 3-variedades 
com fonteira $\bigcup_{j=1}^{V} M_{J}$ (cujas componentes de bordo são as superfícies dadas). Temos também uma relação entre a homologia de $M$ e a topologia do grafo para as quais precisamos provar o seguinte:

Lema 4.2.2. Dado um grafo $\mathcal{G}$ temos $b_{1}(\mathcal{G})=\mu-V+1$, em que $\mu$ é o número de arestas e $V$ é o número de vértices.

Demonstração: Iremos fazer a prova por indução sobre o número de arestas. O grafo com uma aresta e dois vértices claramente satisfaz a propriedade desejada.

Suponha agora que vale para qualquer grafo com $\mu$ arestas e considere um grafo $\mathcal{G}$ com $\mu+1$ arestas. Se o grafo tem loop, remova uma das arestas no loop. O grafo resultante $\mathcal{G}_{r}$ tem $\mu$ arestas, $\operatorname{logo} b_{1}\left(\mathcal{G}_{r}\right)=\mu-V+1$. Se adicionarmos a aresta removida estaremos adicionando um loop. Então temos que $b_{i}(\mathcal{G})=b_{1}\left(\mathcal{G}_{r}\right)+1=(\mu+1)-V+1$.

Se o grafo não tem loop, remova uma aresta e vértice que não esteja ligado a nenhuma outra aresta (uma aresta "final"). O grafo resultante $\mathcal{G}_{r}$ tem $\mu$ arestas e portanto $b_{1}\left(\mathcal{G}_{r}\right)=$ $\mu-V_{r}+1, V_{r}=V-1$. Se adicionarmos a aresta novamente temos que $b_{1}(\mathcal{G})=b_{1}\left(\mathcal{G}_{r}\right)=$ $\mu-V_{r}+1=\mu-(V-1)+1=(\mu+1)-V+1$.

Logo o $1^{\circ}$ número de Betti de um grafo é igual ao seu número ciclomático.

Proposição 4.2.3. Dada uma 3-variedade $M$ orientável e uma coleção de superfícies fechadas orientáveis $S_{i=1}^{\mu}$ em $M$, suponha que $\mathcal{G}$ é o grafo associado a eles. Então, se $\mathcal{G}$ é um grafo bipartido temos que:

$$
\sum_{j=1}^{V} c_{j}+b_{1}(\mathcal{G}) \leqslant b_{2}(M) \leqslant \sum_{j=1}^{V} c_{j}+b_{1}(\mathcal{G})+2 \sum_{i=1}^{V} g_{i}
$$

A igualdade é alcançada quando $g_{i}=0, i=1, \ldots, \mu$.

Demonstração: Por definição temos que

$$
\sum_{j=1}^{V} c_{j}+b_{1}(\mathcal{G})=\sum_{j=1}^{V}\left(b_{2}\left(M_{j}\right)-s_{j}+1\right)+b_{1}(\mathcal{G})=\sum_{j=1}^{V}\left(b_{2}\left(M_{j}\right)\right)-2 \mu+V+b_{1}(\mathcal{G})
$$


pois o grafo é bipartido. Então cada superfície é contada duas vezes uma vez que ela faz fronteira com duas componentes conexas do complemento.

Pelo lema anterior temos que $b_{1}(\mathcal{G})=\mu-V+1$, o que é o suficiente pra provar que $\sum_{j=1}^{V}\left(b_{2}\left(M_{j}\right)\right)-\mu+1 \leqslant b_{2}(M)$. Para isto, usaremos a sequência longa exata de Mayer-Vietoris associada a uma decomposição conveniente de $M$ em 3-variedades. Dado que o grafo é bipartido, o complemento do conjunto singular pode ser separado em duas 3-variedades com bordo $N_{1}$ e $N_{2}$. Seja $N_{1}^{\prime}$ e $N_{2}^{\prime}$ as suas extensões adicionando um colar nos seus bordos em comum, então podemos definir a sequência de Mayer-Vietoris associada a cobertura $\left(N_{1}^{\prime}, N_{2}^{\prime}\right)$ de $M$. Claramente, a homologia de $N_{i}^{\prime}$ coincide com a de $N_{i}$ e que a de $N_{1} \cap N_{2}$ é a mesma que a do bordo em comum. Então a sequência de Mayer-Vietoris pode ser escrita como

$$
\begin{aligned}
& \ldots \rightarrow H_{3}\left(N_{1}\right) \oplus H_{3}\left(N_{2}\right) \stackrel{h_{*}^{3}}{\longrightarrow} H_{3}(M) \stackrel{\Delta_{2}}{\longrightarrow} H_{2}\left(N_{1} \cap N_{2}\right) \ldots \\
& \stackrel{g_{*}^{2}}{\longrightarrow} H_{2}\left(N_{1}\right) \oplus H_{2}\left(N_{2}\right) \stackrel{h_{*}^{2}}{\longrightarrow} H_{2}(M) \stackrel{\Delta_{1}}{\longrightarrow} H_{1}\left(N_{1} \cap N_{2}\right) \ldots
\end{aligned}
$$

Substituindo na sequência a informação que temos obtemos a seguinte sequência

$$
\begin{array}{llllll}
\ldots \longrightarrow & 0 \oplus 0 & \stackrel{h_{*}^{3}}{\longrightarrow} & \mathbb{Z} & \stackrel{\Delta_{2}}{\longrightarrow} & \mathbb{Z}^{\mu} \ldots \\
\stackrel{g_{*}^{2}}{\longrightarrow} \mathbb{Z}^{b_{2}\left(N_{1}\right)} \oplus \mathbb{Z}^{b_{2}\left(N_{2}\right)}+T_{1} \stackrel{h_{*}^{2}}{\longrightarrow} \mathbb{Z}^{b_{2}(M)}+T_{2} \stackrel{\Delta_{1}}{\longrightarrow} \mathbb{Z}^{2 \sum_{i=1}^{\mu} g_{i} \ldots}
\end{array}
$$

onde $g_{i}$ é o genus da superfície $S_{i}$.

$H_{2}(M)$ e $H_{2}\left(N_{1}\right) \oplus H_{2}\left(N_{2}\right)$ podem ter partes de torsão, que são $T_{1}$ e $T_{2}$ respectivamente. Nós apenas estamos preocupados com a dimensão de todos os grupos que aparecem, que depende somentes das partes livres.

Temos que $\sum_{j=1}^{2}\left(b_{2}\left(N_{j}\right)\right)=\sum_{j=1}^{V}\left(b_{2}\left(M_{j}\right)\right)$. Como a sequência é exata temos que $0=\operatorname{Im} h_{*}^{3}=\operatorname{ker} \Delta_{2}$.

Pelo primeiro teorema do isomorfismo

$$
\frac{H_{3}(M)}{\operatorname{Ker} \Delta_{2}}=\frac{\mathbb{Z}}{0} \cong \operatorname{Im}_{2}=\operatorname{Kerg}_{*}^{2} \Rightarrow \operatorname{Kerg} g_{*}^{2} \cong \mathbb{Z}
$$




$$
\begin{gathered}
\frac{H_{2}\left(N_{1} \cap N_{2}\right)}{K e r g_{*}^{2}}=\frac{\mathbb{Z}^{\mu}}{\mathbb{Z}} \cong I m g_{*}^{2}=K e r h_{*}^{2} \Rightarrow \operatorname{Kerh} h_{*}^{2} \cong \mathbb{Z}^{\mu-1} \\
\frac{H_{2}\left(N_{1}\right) \oplus H_{2}\left(N_{2}\right)}{K e r h_{*}^{2}}=\frac{\mathbb{Z}^{\sum_{j=1}^{2} b_{2}\left(N_{j}\right)} \oplus T_{1}}{\mathbb{Z}^{\mu-1}} \cong \operatorname{Im}_{*}^{2}=\operatorname{Ker} \Delta_{1} \Rightarrow \\
\frac{\operatorname{dim}\left(\operatorname{Ker} \Delta_{1}\right)=\sum_{j=1}^{2} b_{2}\left(N_{j}\right)-\mu+1}{\operatorname{Ker} \Delta_{1}}=\frac{\mathbb{Z}^{b_{2}(M)} \oplus T_{2}}{Z^{H_{j=1}^{2} b_{2}\left(N_{j}\right)-\mu+1} \oplus T_{1}} \cong \operatorname{Im} \Delta_{1}=\operatorname{Kerg} g_{*}^{1} \Rightarrow \\
\operatorname{dim}\left(\operatorname{Kerg}_{*}^{1}\right)=b_{2}(M)-\sum_{j=1}^{2} b_{2}\left(N_{j}\right)+\mu-1
\end{gathered}
$$

obtemos que $b_{2}(M)-\sum_{j=1}^{2} b_{2}\left(N_{j}\right)+\mu-1=\operatorname{dim}\left(\operatorname{Kerg}_{*}^{1}\right)$.

Como $2 \sum_{i=1}^{\mu} g_{i} \geq \operatorname{dim}\left(\operatorname{Kerg}_{*}^{1}\right) \geq 0$ substituindo pelos valores já conseguidos acima, chegamos no resultado desejado. Se $g_{i}=0$ para qualquer $i$ ou $g_{*}^{1}$ é injetora teremos a igualdade. Neste caso, como $b_{1}(M)=b_{2}(M)$, determinamos completamente a homologia de $\mathrm{M}$ salvo partes de torsão.

Entretanto, o grafo não determina necessariamente o tipo topológico da 3-variedade. Ainda mais, a topologia do complemento da coleção das superfícies não é determinado completamente pelo grafo na maioria dos casos, como veremos no exemplo a seguir.

Exemplo: Considere o seguinte grafo de uma coleção de superfícies em $\mathbb{R}^{3}$ (ver figura 20): Ele representa dois toros em $S^{3}$. A componente do complemento entre os dois toros é uma 3-variedade com os dois toros como fronteira. Seu $b_{2}$ é igual a 1 e seu $c_{j}=0$, mas isso não distingue do caso onde seu componente é topologicamente $T^{2} \times I$ ( $I$ é um intervalo) ou $T_{s}^{2} \sharp T_{s}^{2}$ (onde $T_{s}^{2}$ é toro sólido). O que distingue essas duas situações é o segundo grupo de homotopia $\pi_{2}$. 

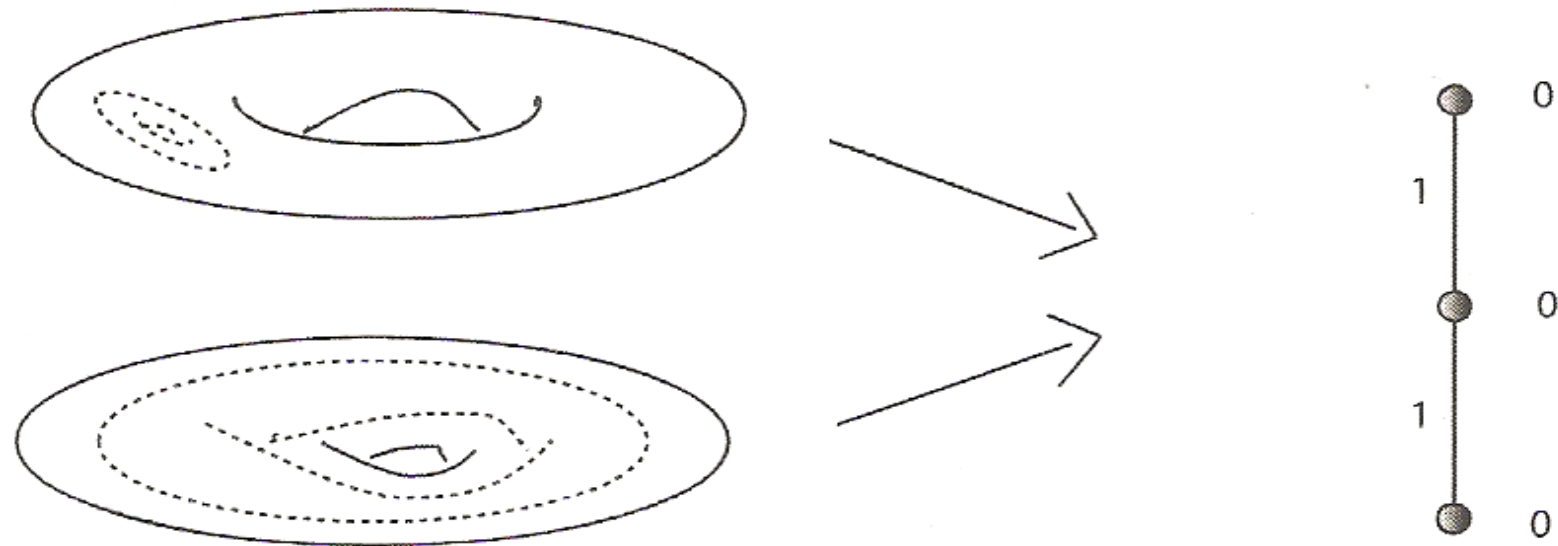

Figura 20: Duas superfícies com o mesmo grafo

Em particular:

Corolário 4.2.4. $M=S^{3} \Rightarrow \mathcal{G}$ é uma árvore e $\sum_{j=1}^{V} c_{j}=0$.

A recíproca não é verdadeira, como podemos ver no exemplo abaixo:

Exemplo: Seja $M=S^{2} \times S^{1}$. Agora considere um círculo $S^{1} \subset S^{2} \times p$, em que $p \in S^{1}$ e seja o toro $T^{2}=S^{1} \times S^{1} \subset S^{2} \times S^{1}$. O grafo associado à este caso é uma árvore porque tem somente uma aresta com peso 1 e dois vértices com peso 0 (cada vértice representa um toro sólido), mas $b_{2}\left(S^{2} \times S^{1}\right)=1$.

Teorema 4.2.5. Qualquer grafo pesado pode ser visto como o grafo de alguma coleção de superfícies fechadas mergulhadas em uma 3-variedade.

Demonstração: Suponha primeiro que $\mathcal{G}$ é um grafo pesado com pesos 0 em seus vértices e pesos $p_{j}$ aleatórios em suas arestas.

Seja $\mathcal{G}_{i}$ o fecho do subconjunto de $\mathcal{G}$ composto pelo vértice $V_{i}$ e todas as semi-arestas (arestas cortadas nos seus pontos médios) incidentes a ele.

Associamos então à $\mathcal{G}_{i}$ uma 3 -variedade com bordo em $\mathbb{R}^{4}$ da seguinte forma: Mergulhe $\mathcal{G}_{i}$ em $\mathbb{R}^{4}$ e seja $R_{i}$ uma vizinhança tubular de $G_{i}$ em $\mathbb{R}^{4}$.

Esta vizinhança tubular pode ser vista como a união de vizinhanças tubulares do vértice $V_{i}$, das semi-arestas e dos pontos finais de cada semi-aresta. Em cada um desses pontos finais podemos considerar o bordo $S^{3}$ de um 4-disco. 
Esta $S^{3}$ pode ser decomposta como a união de dois p-toros orientáveis sólidos com seus bordos convenientemente identificados, onde p é o peso da aresta correspondente.

Deste modo, tomando o bordo de $R_{i}$ e removendo dele o interior de um dos $p_{j}$-toros orientáveis sólidos para cada um dos seus pontos finais, obtemos uma 3-variedade $M_{i}$ com bordo, cujo bordo tem tantas componentes quanto arestas incidentes em $V_{i}$, e cada um destas componentes de bordo é uma superfície fechada orientada, cujo genus é determinado pelo peso da aresta correspondente.

Unindo convenientemente todas essas 3-variedades pelo seu bordo de acordo com a distribuição dos seus vértices no grafo obtemos uma 3-variedade compacta com bordo M e uma coleção de superfícies orientáveis fechadas em $M$ cujo grafo é $\mathcal{G}$.

Quando os vértices de $\mathcal{G}$ tem pesos não nulos, precisamos apenas adicionar em cada região $M_{i}$ da construção anterior tantas alças do tipo $S^{2} \times I$ quanto indicadas pelo peso do vértice correspondente. 


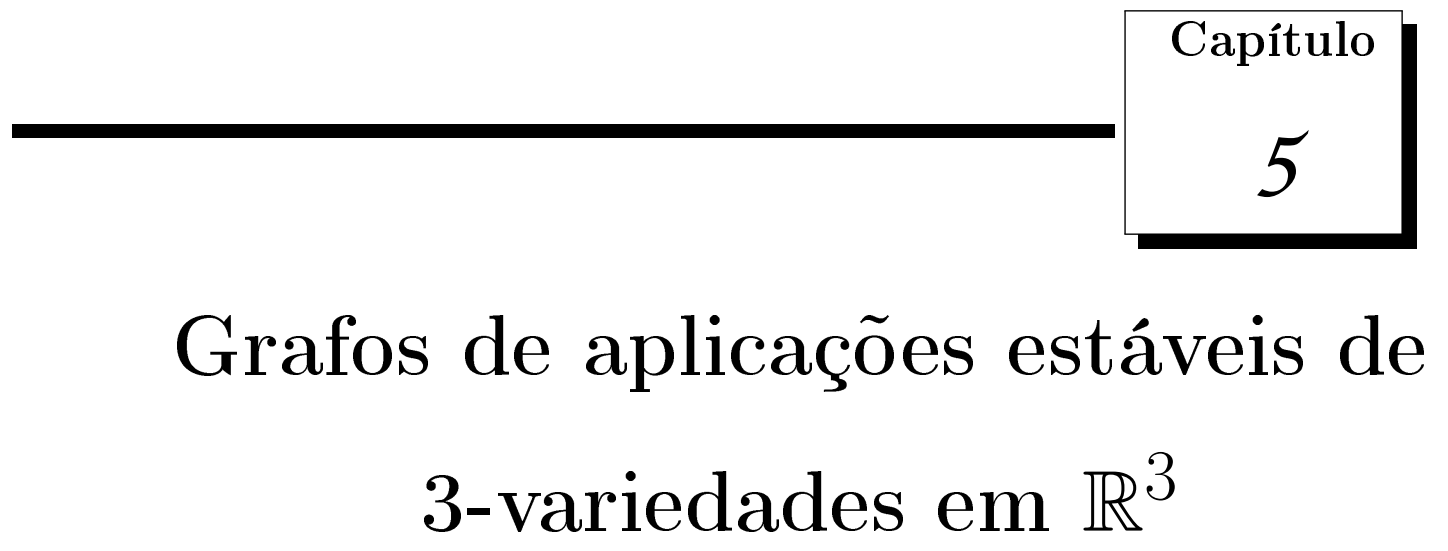

Agora, dada uma aplicação estável $f: M \rightarrow \mathbb{R}^{3}$, vamos considerar o conjunto singular de $f$ como a coleção de superfícies para construirmos o grafo. O grafo correspondente é definido como o grafo de $f$.

Para esse estudo dos grafos junto com as aplicações estáveis foi usado [9] e [10].

Não é difícil de ver que, como no caso de aplicações estáveis de superfícies orientáveis fechadas no planos, se uma 3-variedade $M$ é orientável, então o grafo de qualquer aplicação estável de $M$ em $\mathbb{R}^{3}$ precisa ser bipartido, pois cada componente do conjunto singular separa (globalmente) $M$ em regiões diferentes, uma em que preserva a orientação e outra em que reverte. Deste modo aparecem várias questões que podem ser feitas:

- Qualquer grafo pode ser representado por uma aplicação estável de uma 3-variedade fechada em $\mathbb{R}^{3}$ ?

- Qualquer coleção de superfícies fechadas disjuntas mergulhadas em uma 3-variedade fechada $M$ pode ser o conjunto singular de uma aplicação estável de $M$ em $\mathbb{R}^{3}$ ?

- Quais são todos os possíveis grafos para aplicações estáveis de uma dada 3-variedade fechada $M$ em $\mathbb{R}^{3}$ ?

- Para um dado grafo $\mathcal{G}$, como construir diferentes $\mathcal{A}$ - classes de aplicações estáveis 
em $M$ cujo grafo seja $\mathcal{G}$ ?

Dada uma aplicação $f: M \rightarrow N$, onde $M$ e $N$ são n-variedades e uma (n-1)subvariedade $\sum, f$ é dita ser uma $\sum$-imersão se $\left.f\right|_{M \backslash \sum}$ e $\left.f\right|_{\sum}$ são imersões e o conjunto singular de $f$ é precisamente $\sum$ que é exclusivamente composto pelos pontos de dobra da $f$. Então temos o seguinte resultado que não será provado, apenas o usaremos para demonstrarmos outros resultados mais adiante:

Teorema 5.0.6. [1] (Y. Eliashberg) Seja M uma n-variedade estavelmente paralelizável, fechada e conexa, e $\sum$ uma (n-1)-subvariedade fechada não vazia que divide $M$ em duas variedades $M_{1}$ e $M_{2}$ (possivelmente desconexas) com bordo comum $\sum$. Então

a) se $n=1,3,7$, então existe uma $\sum$-imersão $M \rightarrow \mathbb{R}^{n}$;

b) se né par, então existe uma $\sum$-imersão $M \rightarrow \mathbb{R}^{n}$ se e somente se $\mathcal{X}\left(M_{1}\right)=\mathcal{X}\left(M_{2}\right)$;

c) se n é impar e diferente de 1, 3 ou 7 , então uma $\sum$-imersão $M \rightarrow \mathbb{R}^{n}$ existe se $e$ somente se $\mathcal{X}\left(\sum\right) \equiv 2 \mathcal{X}^{*}(M)(\bmod 4)$, onde $\mathcal{X}^{*}(X)=\sum_{i=0}^{[\operatorname{dim} X / 2]}(-1)^{i} b_{i}(X)$.

Variedades estáveis paralelizáveis são caracterizadas por Hirsch como variedades orientáveis que podem ser imersas em $\mathbb{R}^{n+1}$.

Este resultado pode ser reinterpretado na linguagem de grafos da seguinte forma: $\sum$ divide $M$ em duas variedades (possivelmente desconexas) $M_{1}$ e $M_{2}$ com bordo em comum $\sum$, significa que o grafo deve ser bipartido.

Teorema 5.0.7. Qualquer grafo pesado pode ser visto como uma coleção de superfícies mergulhadas em uma 3-variedade.

Na demonstração deste teorema, esta 3-variedade é construída como uma 3-esfera com alças, que é orientável e pode ser mergulhada em $\mathbb{R}^{4}$, e desta forma é estavelmente paralelizável. Isto junto com o teorema de Eliashberg e o fato de que dada qualquer $\sum$ imersão podemos encontrar uma aplicação (dobra) estável tão próxima quanto quisermos (de tal forma que o conjunto singular equivalente) nos mostra o seguinte:

Corolário 5.0.8. Qualquer grafo bipartido é o grafo de alguma aplicação (dobra) estável de uma $S^{3}$ com alças em $\mathbb{R}^{3}$.

No caso particular da 3-esfera, temos o seguinte: 
Corolário 5.0.9. Qualquer árvore com $c_{j}=0, \forall j=1, \ldots, V$ é o grafo de uma aplicação (dobra) estável $f: S^{3} \rightarrow \mathbb{R}^{3}$.

A partir de agora vamos mostrar como construir grafos associados à aplicações estáveis começando de um grafo básico. E a motivação vem do seguinte fato:

Dada qualquer 3-variedade estavelmente paralelizável $M$, graças ao teorema de Eliashberg, existe uma aplicação estável de $M$ em $\mathbb{R}^{3}$ com uma $S^{2}$ como conjunto singular dividindo a variedade em duas regiões, uma difeomorfa a uma 3-bola e outra equivalente por homotopia à $M$ menos um ponto.

Isto nos dá as condições necessárias para começar a investigar os possíveis grafos que podem ser associados à aplicações estáveis sobre uma 3-variedade M, i.e. começando do grafo onde a única aresta tem peso zero e um dos vértice tem pesos zero e outro vértice tem peso $b_{2}(M)$.

Também podemos usar separações de Heegaard como origem de grafos básicos.

Definição 5.0.1. Um corpo com alças de genus g é uma variedade obtida ao se adicionar g 1-alças a uma 3-bola. Em outras palavras, pegue uma 3-bola com $2 g$ discos disjuntos em seu bordo, e considere como g pares de discos. Para cada par, anexe uma cópia de $[0,1] \times D^{2}$ ao longo de $\{0,1\} \times D^{2}$. Se a aplicação de anexar reverte a orientaçãa, o corpo com alças é orientável.

Definição 5.0.2. Dados dois corpos com alças orientáveis $W_{1}$ e $W_{2}$ de mesmo genus $g$, e um difeomorfismo que reverte orientação $f: \partial W_{1} \rightarrow \partial W_{2}$, podemos construir uma variedade orientável $M^{3}$ como

$$
M^{3}=W_{1} \coprod_{\partial W_{1}=\partial W_{2}} W_{2}
$$

A decomposição de $M$ em $W_{1}$ e $W_{2}$ é chamada uma divisão de Heegaard de $M$ e a superfície $H=\partial W_{1}=\partial W_{2}$ é chamada uma superfície de Heeegaard.

Teorema 5.0.10. [5] Todas 3-variedades possuem uma divisão de Heegaard.

Dada uma divisão de Heegaard de uma 3-variedade estavelmente paralelizável $M$, a superfície de Heegaard é separável. Pelo teorema de Eliashberg então existe uma aplicação 
dobra de $M$ em $\mathbb{R}^{3}$ que tem essa superfície como conjunto singular. O grafo associado a esta aplicação tem 2 vértices e uma aresta. Ambos vértices tem peso zero, pois o segundo número de Betti de corpos com alças é igual à zero, e a aresta tem peso g (genus da superfície de Heegaard).

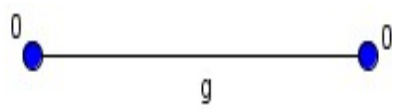

Figura 21: Grafo associado a uma divisão de Heegaard de genus g

Tomando a divisão de Heegaard mínima de uma dada variedade, i.e. a divisão de Heegaard com a superfície de Heegaard de genus mínimo (conhecido como genus de Heegaard da variedade) temos um exemplo muito básico de um grafo de uma aplicação estável de $M$ em $\mathbb{R}^{3}$. Então por transições convenientes e cirurgias, podemos obter diferentes exemplos de aplicações estáveis em $M$ ou em somas conexas de $M$ com outras 3-variedades. Uma vez que o espaço das aplicações estáveis (com a topologia $C^{\infty}$ de Whitney) de uma 3-variedade conexa $M$ em $\mathbb{R}^{3}$ é conexo por caminhos, podemos obter qualquer aplicação estável de $M$ em $\mathbb{R}^{3}$ de uma aplicação basica dada. Mas isto não é uma tarefa trivial. Por exemplo, por Eliashberg podemos ter dois toros como o conjunto dobra de uma aplicação estável de $S^{3}$ em $\mathbb{R}^{3}$, mas encontrar um caminho entre esta aplicação e o exemplo simples dobrando a 3-esfera ao longo do seu equador ainda é um problema em aberto.

\subsection{Transições de Codimensão 1}

Na figura abaixo temos estratos de codimensão 1 no espaço das aplicações suaves de uma 3-variedade em $\mathbb{R}^{3}$ com suas transições (a seta aponta na direção do cruzamento positivo do estrato) e notações. As ilustrações abaixo (figura 22) representam a deformação local na imagem do conjunto singular quando cruza o estrato de codimensão 1 do discriminante (subconjunto de aplicações não estáveis). A linha preta representa arestas cuspidais.

Para mostrar o papel das transições nós construíremos um exemplo de uma aplicação 


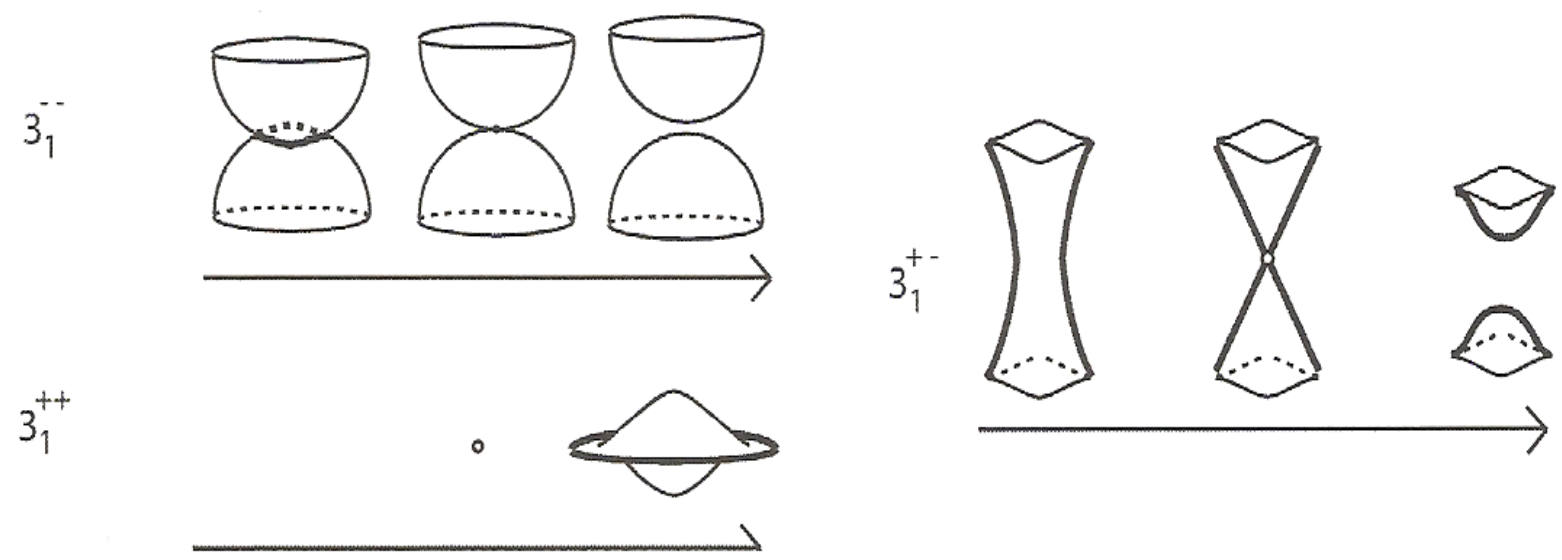

Figura 22: Transições de alguns estratos de codimensão 1

estável que passa por certas singularidades e veremos como o grafo associado irá variar. Lembre que as imagens na figura a seguir representam o conjunto discriminante, não o conjunto singular. O conjunto discriminante é bidimensional, mas para podermos simplificar a figura desenhamos apenas uma seção das superfícies em questão. As figuras são simétricas e o conjunto discriminante é obtido como uma superfície de revolução através do eixo de simetria. Assim, um círculo na imagem representa uma esfera no conjunto discriminante.

Começamos com uma aplicação $f: S^{3} \rightarrow \mathbb{R}^{3}$ cujo conjunto singular é uma simples $S^{2}$ sem arestas cuspidais. Então cruzamos um estrato $3_{1}^{++}$e uma nova $S^{2}$ topológica é criada dentro da outra. Então esticamos a aresta cuspidal (isto não muda a $\mathcal{A}$-classe da aplicação) até cruzar o estrato $3_{1}^{--}$na direção positiva de sua transição (Caso 2 abaixo). Terminamos com uma aplicação estável cujo conjunto singular (e conjunto discriminante) é uma coleção de três 2-esferas sem cúspides. Todos os pesos dos vértices e das arestas dos grafos abaixo são zero (ver figura 23).

Na figura 24 temos outro exemplo. Novamente, somente uma seção do conjunto discriminante é desenhada e o mesmo é obtido como uma revolução sobre o eixo de simetria, tendo assim uma superfície de revolução. Aqui obtemos um toro com arestas cuspidais dentro de uma esfera (Caso 1 abaixo). 


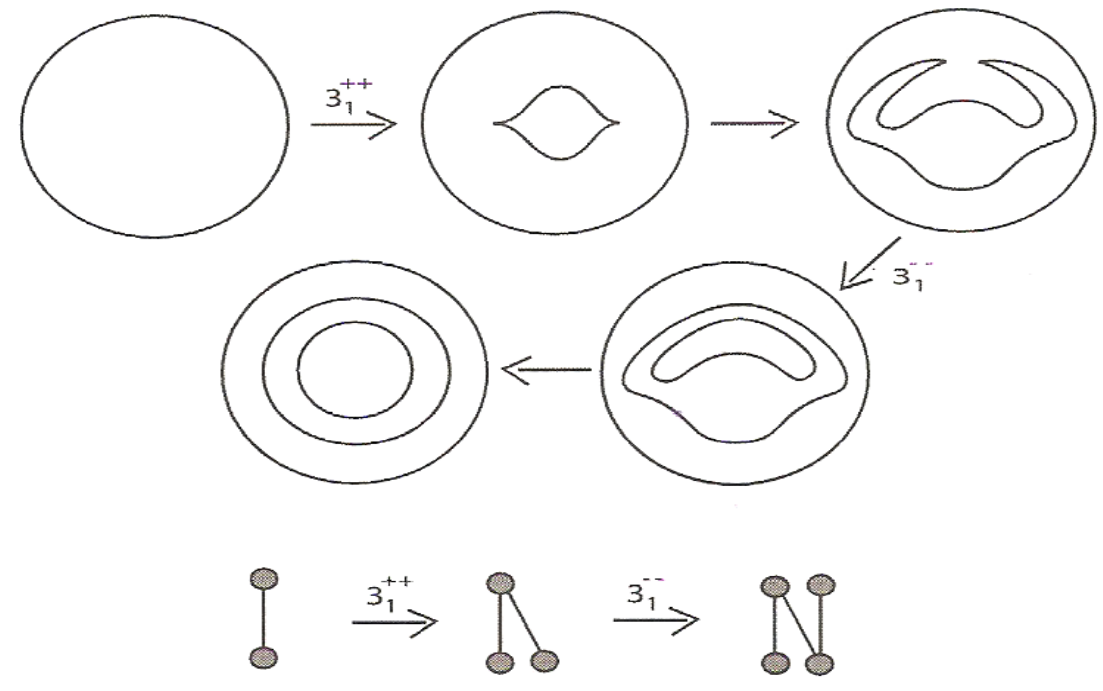

Figura 23: Exemplo de uma aplicação submetida a transições de codimensão 1 e seu grafo.

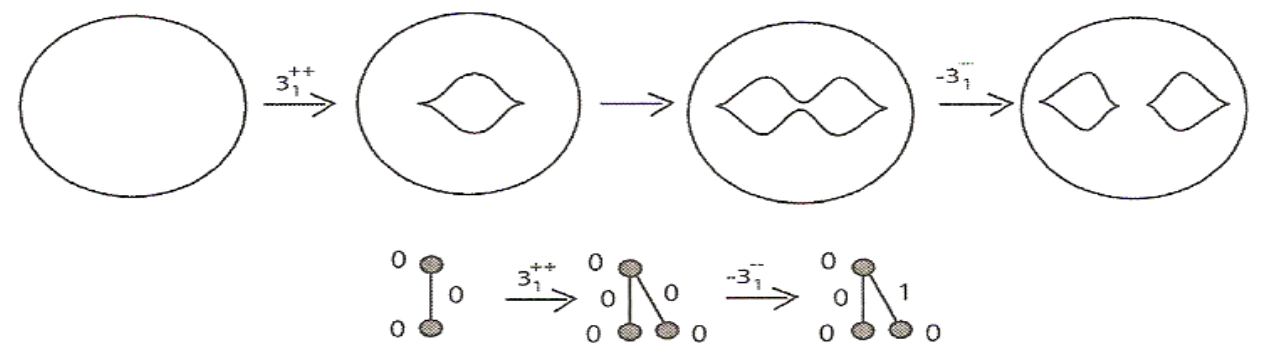

Figura 24: Um toro com arestas cuspidais dentro de uma esfera 
Podemos ver que as únicas transições que podem adicionar ou remover arestas (e, de tal forma, um vértice), ou mudar o peso de uma aresta são as singularidades $3_{1}$. Em particular, a singularidade $3_{1}^{++}$cria (ou remove) uma aresta com peso zero que termina em um vértice de peso zero. Por outro lado, singularidades $3_{1}^{+-}$e $3_{1}^{--}$, quando indo na direção positiva de sua transição, mudam o peso de uma aresta (mudam o peso do genus da superfície que está sujeita a essa singularidade) se as duas componentes locais no fim da transição pertencem a mesma componente conexa, e cria uma nova aresta no outro caso.

E com essas transições podemos provar o seguinte:

Teorema 5.1.1. Qualquer árvore com $c_{j}=0, \forall j=1, \ldots, V$ pode ser realizado como o grafo de uma aplicação estável $f: S^{3} \rightarrow \mathbb{R}^{3}$.

Demonstração: A ideia é criar um caminho no espaço das aplicações $C^{\infty}\left(S^{3}, \mathbb{R}^{3}\right)$ entre uma aplicação básica conhecida e outra aplicação cujo seu grafo é o mesmo que a árvore dada. Isto será feito indutivamente aplicando as transições acima convenientemente, de forma que mudemos o grafo da aplicação inicial até chegarmos na aplicação desejada. Podemos começar de um grafo com uma única aresta com peso zero ligando dois vértices de peso também zero. Este grafo pode ser realizado como o grafo de uma aplicação cujo conjunto singular é uma simples esfera. Por exemplo, podemos pegar a aplicação estável obtida por dobrar a 3-esfera em seu equador e mandar as duas partes homeomorficamente sobre uma 3 -bola em $\mathbb{R}^{3}$. Por meio de singularidades $3_{1}^{++}$podemos adicionar quantas arestas de peso zero desejarmos. Assim que obtemos a árvore desejada, basta ajustar os pesos das arestas para conseguirmos, com exatidão, o grafo que estamos buscando. Isto é feito através das singularidades $3_{1}^{+-}$ou das singularidades $3_{1}^{--}$. Como a construção toda foi feita apenas com cruzamentos de certos estratos de codimensão 1 em $C^{\infty}\left(S^{3}, \mathbb{R}^{3}\right)$ é claro que a aplicação obtida é uma aplicação estável de $S^{3} \mathrm{em} \mathbb{R}^{3}$.

Outro exemplo de como transições de codimensão 1 podem ser usadas para determinar grafos de aplicações estáveis em uma dada 3-variedade é o seguinte: 
Exemplo: Um tritoro $\left(S^{1} \times S^{1} \times S^{1}\right)$ tem genus de Heegaard 3 .

Podemos então começar de uma aplicação estável associada a este grafo (em virtude do Teorema de Eliashberg) e aplicar convenientes 1-transições a fim de obter todos os outros grafos associados a aplicações estáveis em $S^{1} \times S^{1} \times S^{1}$. Observe que este processo também nos fornece todas as coleções possíveis de superfícies fechadas que separa $S^{1} \times S^{1} \times S^{1}$ em dois pedaços (não necessariamente conexas).

\subsection{Cirurgias de Aplicações Estáveis}

Introduziremos agora dois tipos de cirurgia entre aplicações estáveis e vamos analisar seus efeitos no grafo.

Considere aplicações estáveis $f: M \rightarrow \mathbb{R}^{3}$ e $g: N \rightarrow \mathbb{R}^{3}$ em que $M$ e $N$ são 3variedades. Definimos a soma conexa $f \sharp g: M \sharp N \rightarrow \mathbb{R}^{3}$ como segue: começamos removendo duas 3-bolas $B_{1}$ e $B_{2}$ em $M$ e $N$, respectivamente, tais que suas intersecções com o conjunto de singular de $f$ e $g$ são dois discos $D_{1}$ e $D_{2}$ de pontos dobra (i.e. sem arestas cuspidais ou curvas dobras duplas). Então juntamos as variedades em $\partial B_{1}$ e $\partial B_{2}$ por um tubo $S^{2} \times I$ com um tubo $S^{1} \times I$ que une $\partial D_{1}$ com $\partial D_{2}$ ( $I$ é um intervalo). A projeção no $\mathbb{R}^{3}$ deste tubo não intersecciona nenhuma parte do conjunto discriminante. Para poder fazer isto os conjuntos discriminantes originais de $f$ e $g$ podem ser feitos para pertencerem a diferentes semi-espaços de $\mathbb{R}^{3}$. O conjunto discrimante da aplicação resultante é a soma conexa dos conjuntos discriminantes de $f$ e $g$.
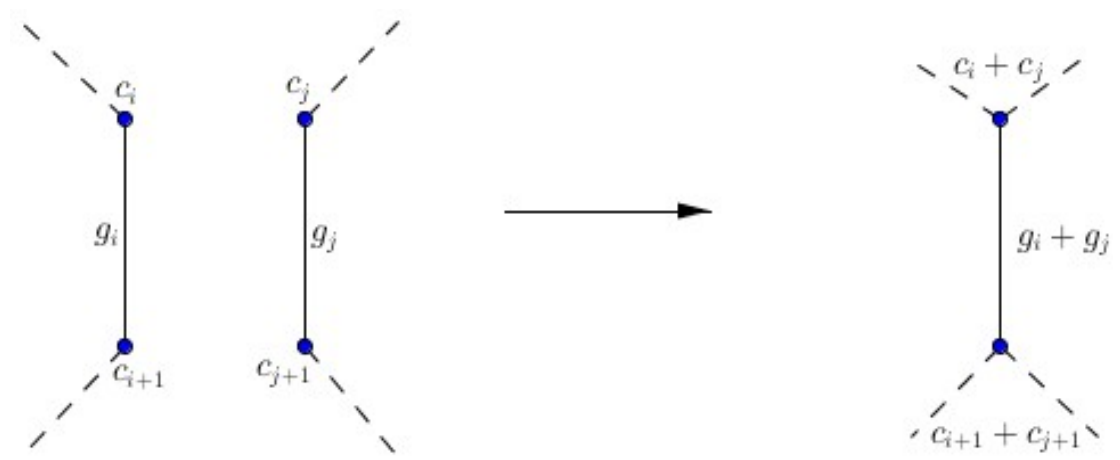

Figura 25: Efeito de uma cirurgia horizontal nos grafos 
Seja $\mathcal{G}(f)$ o grafo associado a aplicação $f$. O efeito desta cirurgia sobre $\mathcal{G}(f)$ e $\mathcal{G}(g)$ é mostrado na figura 26. A soma conexa dos conjuntos singulares (que não é nada mais que a soma conexa de superfícies) se torna uma superfície com genus igual a soma dos genus das duas superfícies envolvidas. O peso dos vértices são adicionados também, pois se $M_{i}$ e $M_{j}$ são as regiões correspondentes aos dois vértices envolvidos com pesos $c_{i}$ e $c_{j}$ e $M_{k}$ é a região resultante, então temos

$$
c_{k}=b_{2}\left(M_{k}\right)-s_{k}+1=b_{2}\left(M_{i}\right)+b_{2}\left(M_{j}\right)-\left(s_{i}+s_{j}-1\right)+1=c_{i}+c_{j}
$$

Falaremos agora de outro tipo de cirurgia. Dada uma aplicação estável $f: M \rightarrow \mathbb{R}^{3}$ em uma 3-variedade $M$ não necessariamente conexa, tome duas 3-bolas em $M$ tais que elas não interseccionem o conjunto singular e tais que tenham a mesma imagem em $\mathbb{R}^{3}$, uma delas preservando a orientação e a outra aplicada revertendo orientação. Depois una os bordos das duas 3-bolas removidas com um tubo $S^{2} \times I$. Esse tubo adiciona uma $S^{2}$ ao conjunto singular adjacente aos dois componentes do conjunto singular da aplicação original de onde as duas 3-bolas foram retiradas. Chamaremos a aplicação resultante de $f_{v}$. Os dois vértices envolvidos, após a cirurgia, tem um novo gerador de $H_{2}$, a $S^{2}$ adicionada ao conjunto singular, mas eles tem uma nova superfícies no bordo (a mesma $S^{2}$ ), então o peso não varia. O grafo resultante pode ser visto na figura 26.

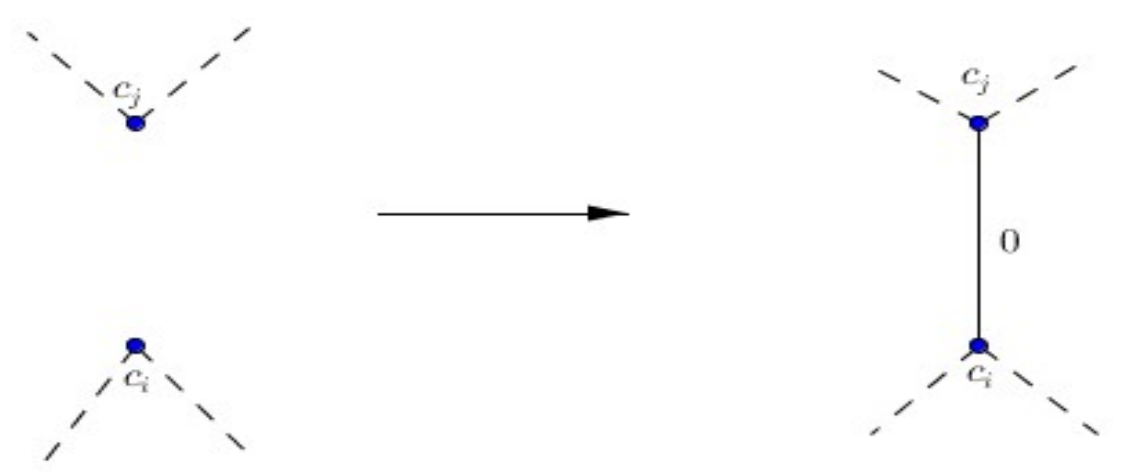

Figura 26: Efeito de uma cirurgia vertical nos grafos 


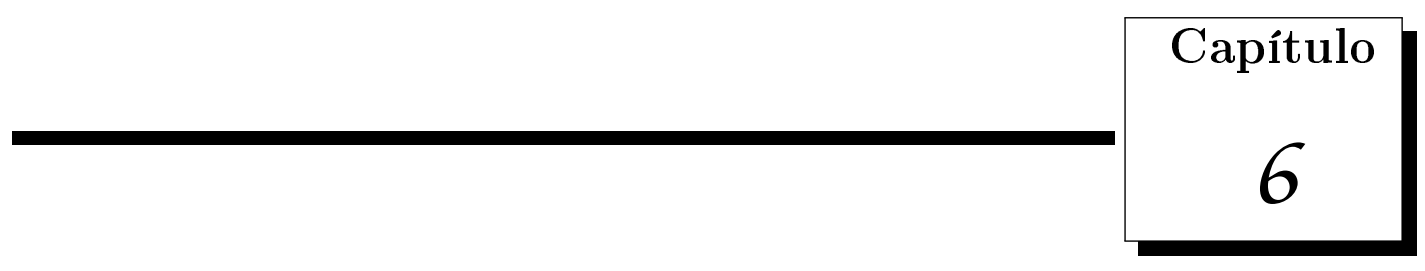

\section{Considerações finais}

Tendo em vista o estudo desenvolvido, enunciamos abaixo questões que podem ser estudadas no futuro:

a) Aplicações estáveis de superfícies fechadas não orientáveis compactas em $\mathbb{R}^{2}$.

b) Caracterização das superfícies compactas (imersas) em $\mathbb{R}^{3}$ que podem ser imagem do bordo de uma 3-variedade imersa.

c) Estudo dos grafos associados às aplicações de Gauss estáveis sobre superfícies imersas em $\mathbb{R}^{3}$ e 3 -variedades em $\mathbb{R}^{4}$.

d) Invariantes de Vassiliev de aplicações estáveis de superfícies em 3-variedades em $\mathbb{R}^{4}$.

e) Propriedade do levantamento padrão para superfícies em $\mathbb{R}^{4}$ e sua relação com os invariantes de Arnol'd para curvas planas. 


\section{Referências Bibliográficas}

[1] Eliashberg, Y. On singularities of folding type. In Math. USSR Izv. 4. 1970, pp. 1119-1134.

[2] Giblin, P. Graphs, Surfaces and Homology. Cambridge University Press, 2010.

[3] GiBSon, C. G. Singular points of smooth mappings. Research notes in mathematics. Pitman, 1979.

[4] Hacon, D., Mendes de Jesus, C., And Romero Fuster, M. C. Topological invariants of stable maps from a surface to the plane from a global viewpoint. In Real and complex singularities, vol. 232 of Lecture Notes in Pure and Appl. Math. Dekker, New York, 2003, pp. 227-235.

[5] Hempel, J. 3-Manifolds. Princeton University Press, Princeton, N. J., 1976. Ann. of Math. Studies, No. 86.

[6] Hirsch, M. W. Differential topology. Graduate texts in mathematics. SpringerVerlag, 1976.

[7] Lima, E. L. Homologia basica. Projeto Euclides. IMPA, 2009.

[8] Mendes de Jesus, C., Oset Sinha, R., And Romero Fuster, M. C. Global topological invariants of stable maps from 3-manifolds to $\mathbb{R}^{3}$. Tr. Mat. Inst. Steklova 267, Osobennosti i Prilozheniya (2009), 214-225.

[9] Oset Sinha, R. Topological invariants of stable maps from 3-manifolds to threespace. Tese de doutorado. Universitat de València. 
[10] Oset Sinha, R., And Romero Fuster, M. C. Graphs of stable maps from 3-manifolds to $\mathbb{R}^{3}$.

[11] Silva Machado, D. Invariante global de aplicações estáveis de superfície no plano. Dissertação de mestrado. Universidade Federal de Viçosa, 2010. 